Journal of Al-Azhar University Engineering Sector

Vol.16, No. 58, January, 2021, 85-100

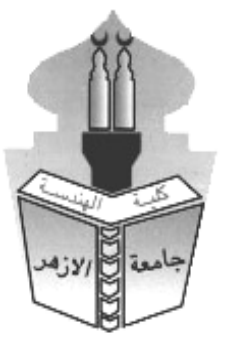

\title{
ELEMENTS OF DEVELOPING LOCAL MANAGEMENT OF URBAN IN EGYPT
}

\author{
Ahmed Saad Dabour* and Zaker Mousa Tammam \\ Architecture \& Urban planning Department, Faculty of Engineering, Al-Azhar University, \\ Cairo, Egypt. \\ *Corresponding Author E-mail: dr.dabour@azhar.edu.eg
}

\begin{abstract}
:
Urban affairs management has a direct impact on the city's image, the quality of life in it, and the citizen's living in general. The responsibility for urban affairs is shared between the central government and the local administration, city's urbanis related to the efficiency of the local administration in organizing and managing the various fields, This administration depends on several key elements. These elements include the organizational structure of the administration and some of the systems and legislations that rule urban management, as well as the funding allocated for that, therefore the research dealt with many points that fall under those elements, including the concept of local administration, the components of local administration and the organizational structure, as well as the objectives and specializations of the local administration in addition to some global systems in local administration, the research also deals with historical background on local administration in the constitution, as well as the local administration's law and the unified building law. The research also reviews the funding process allocated to urban management, and finally the research ends with a number of results and recommendations.
\end{abstract}

KEYWORDS: Urban-Urban Affairs, Local Administration, Decentralization, Municipalities.

$$
\begin{aligned}
& \text { عناصر تطوير الإدارة المحلية للعمران في مصر } \\
& \text { أحمد سعد عبد الرحمن دبور * و ذاكر موسي تمام } \\
& \text { قسم هندسة العمارة، قسم التخطيط العمر اني، كلية الهندسة، دمدئ، جامعة الأز هر ، القاهرة، مصر. }
\end{aligned}
$$

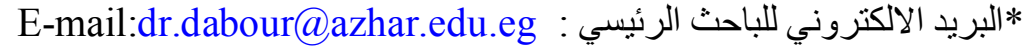

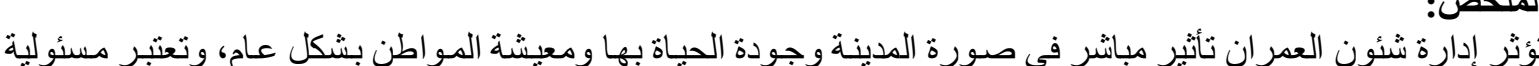

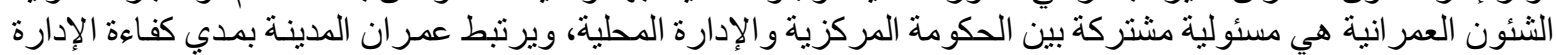

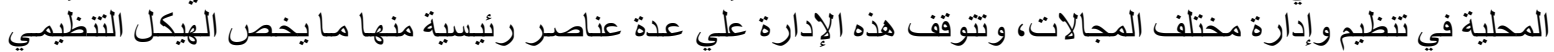

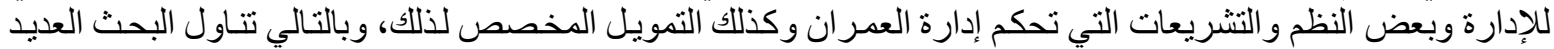

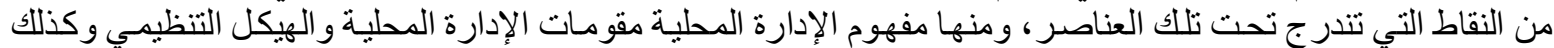

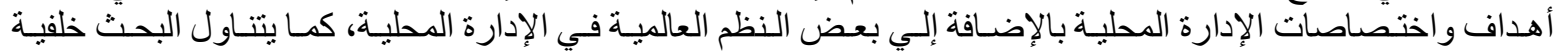

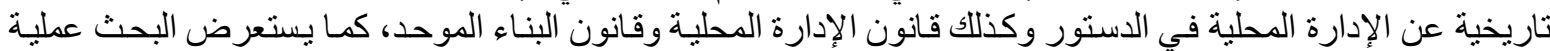

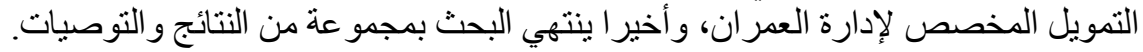




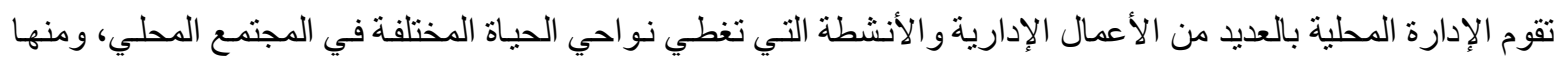

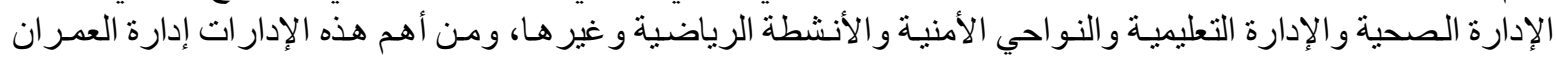

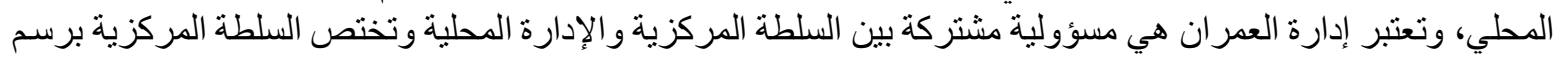

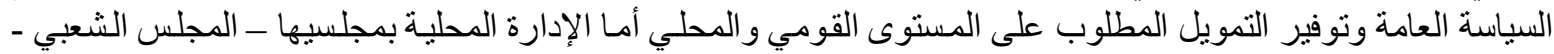

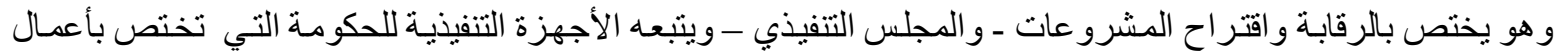

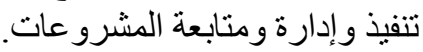

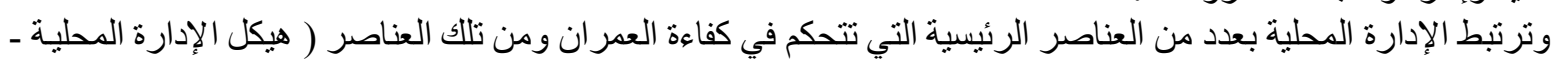

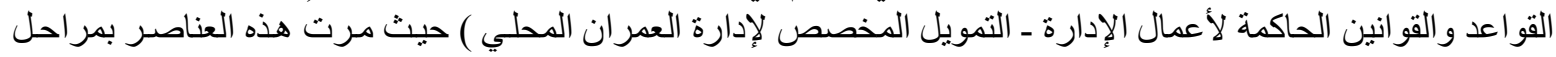
تغيير وتطوير كثيرة ولم تؤنتي ثمار ها حتى ألان.

المشكنة

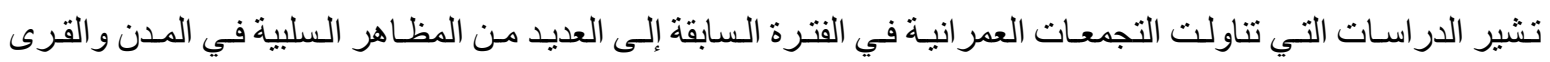

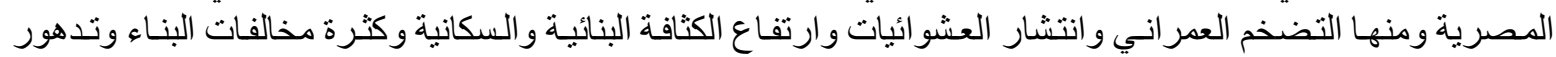

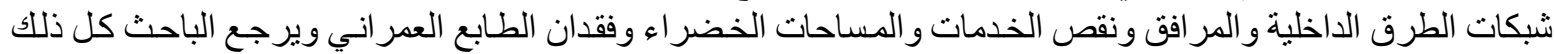
لخلل ما في الإدارة العمر انية المحلية أدي إلي خلل في كفاءة العمران. فرضية البحث يفترض الباحث أن كفاءة الإدارة المحلية في تحسين العمر ان مرتبط بعو امل رئيسية ثنلاث ( نظام الإدارة المحلية ـ التمويل

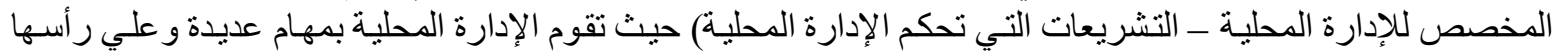
الثئون العمر انية، ما يستدعي المزيد من البحث و الدر اسة للوقوف على مدي أهمية تلك العوارة التل في تحسين حالة العمر ان.

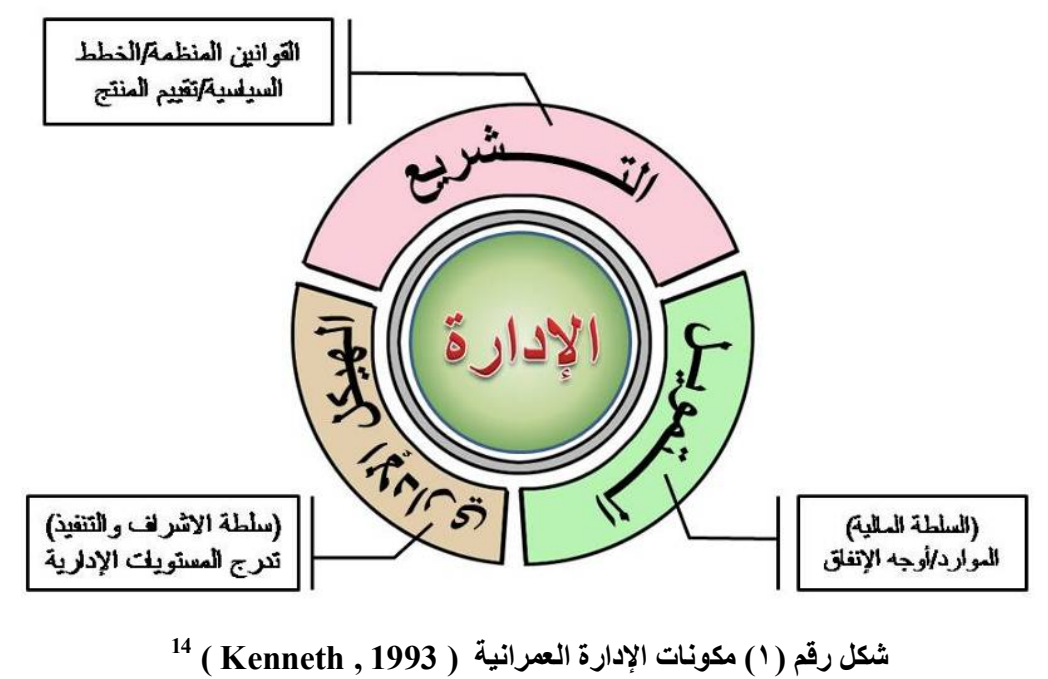

منهبية البحث

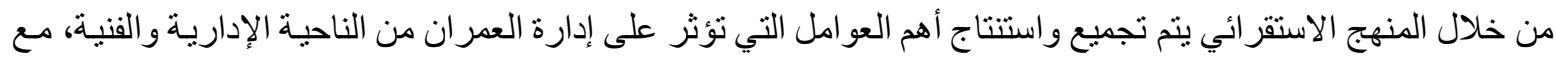

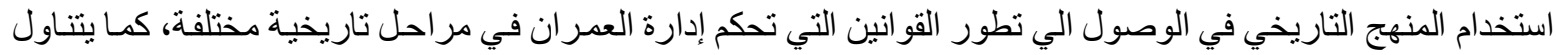

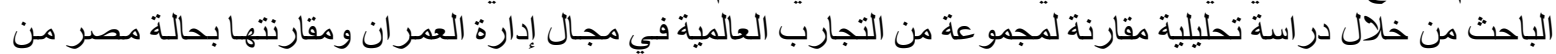

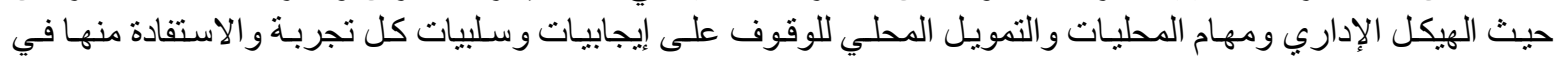

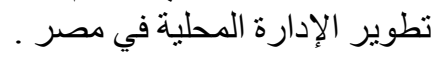


أهداف البحث

- - - تحديد العناصر الرئيسية التي تؤثر في إدارة العمران المحلي

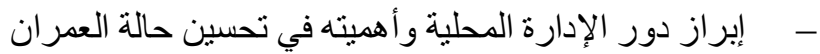

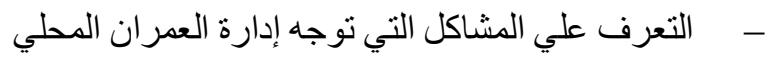

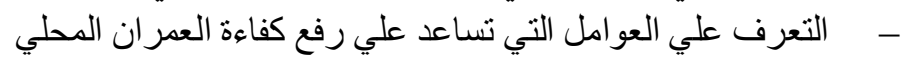
الهمية البحث

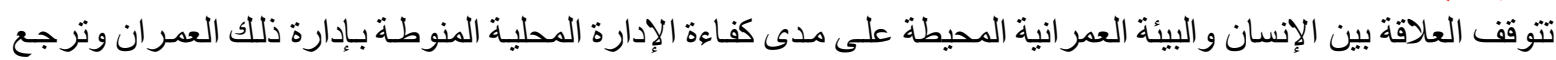

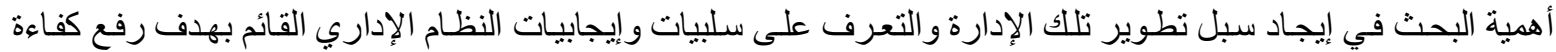

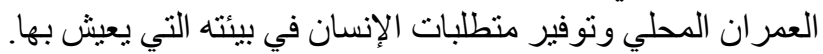

محتويات البحث

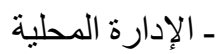
ـ النظم و التشريعات التي تحكم الإدارة المحلية

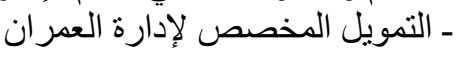

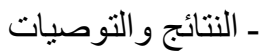

- إلادارة المحلية

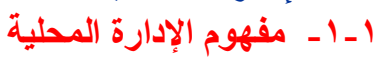

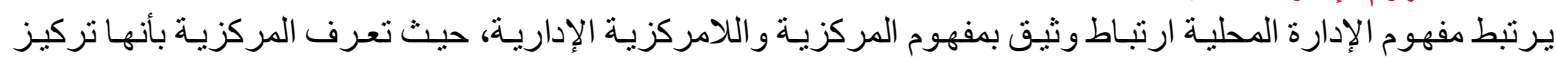

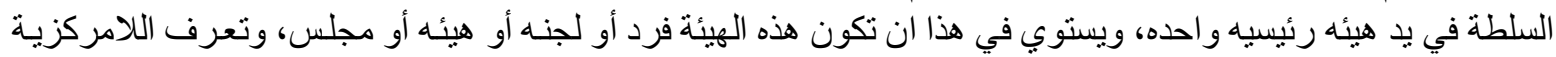

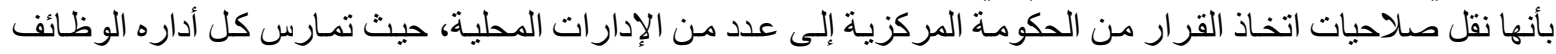

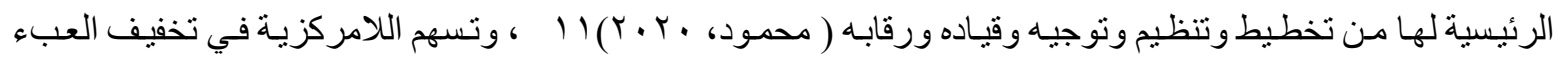

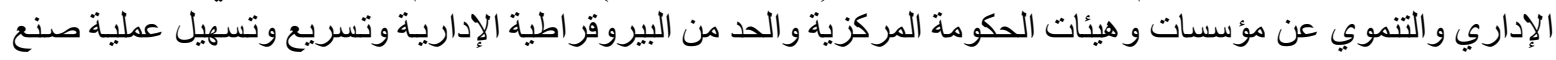
القرار الإداري

ويعتبر .. تنازل هيئات الحكم المركزية عن جز ء من صلاحيتها لصالح هيئات محلية تتعايش مـع مشكلات السكان المحليين

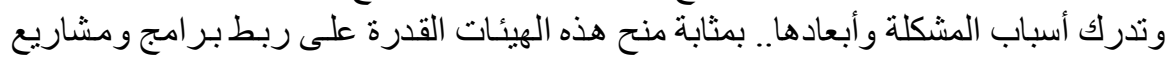

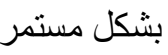

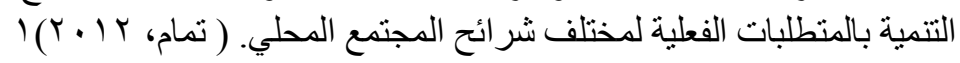
وبهذا تعرف اللامركزية بأنها عمليه انتقال السلطة من الحكومـة المركزية و المستويات الأعلى في الدولة إلى المستويات الأقل، وللمركزية أنماط متعددة ( التنازل - التفويض - إبطال المركزية ـ التجريد ).
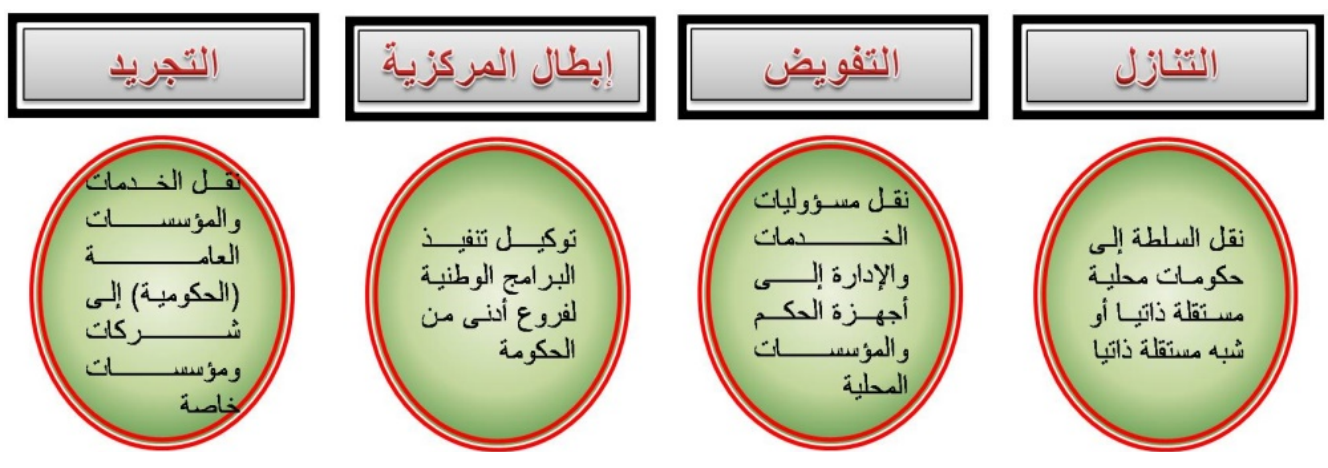

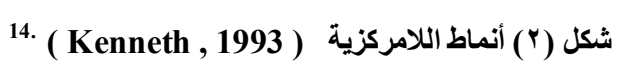

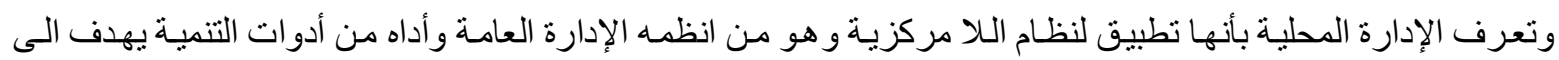

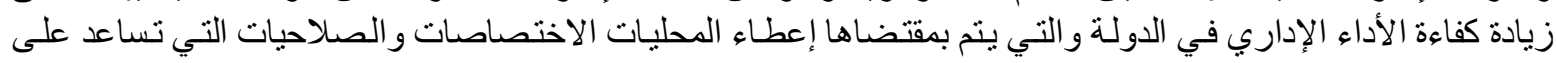


سر عه وسهوله اتخاذ القرار بعيدا عن سيطرة السلطة المركزية مع ارتباط هذا القر ار بتحقيق السياسات و الأهداف التنمويـة للاولة.

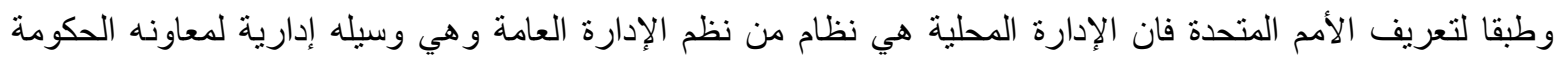

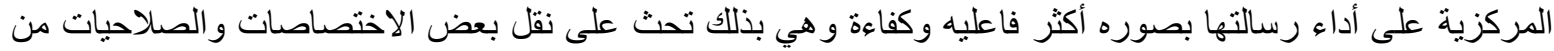
الحكومة المركزية إلى المحليات لمواجهه مسؤولياتها في إطار توزيع الأدوار الوظيفية و تقسيم العمل بين المستويين المركزي و المحلي.

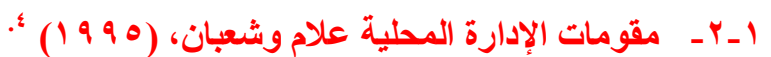

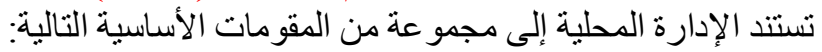

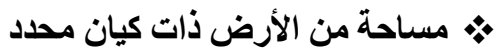

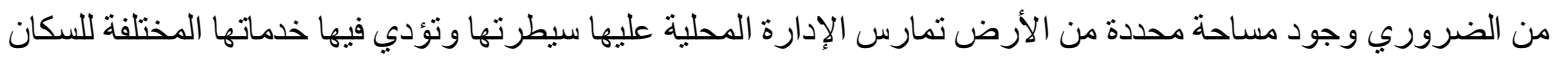

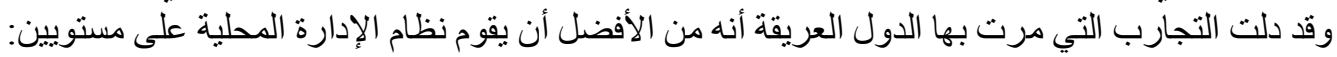

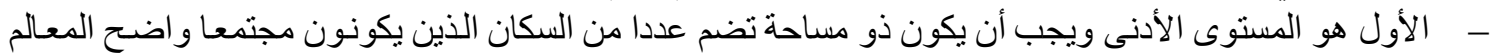

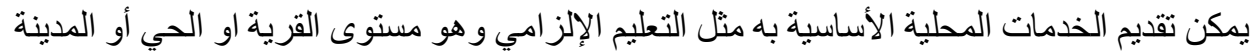

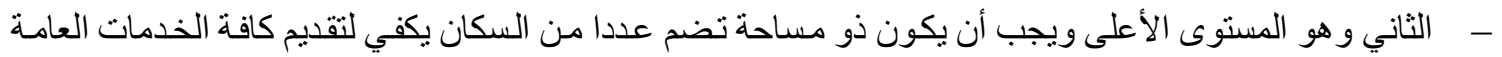

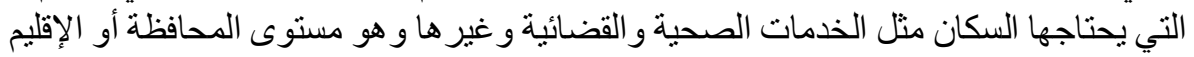

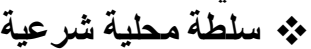

تستند السلطة المحلية إلى الدستور ولئة والقانون ويحدد القانون و اللو ائح التنفيذية المكملة له كيفية تشكيل الإدارة كما يوضح اختصاصاتها ومسؤولياتها المختلفة، وهو ما سنعرض ولفئل له بالتفصيل فيما بعد.

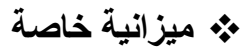

من الضروري أن يكون للسلطة المحلية إير ادات تستطيع من خلالها الإنفاق على متطلبات تأدية أعمالها من خلال ميز انية تضعها حيث تتكون المو ارد من عناصر ثلاث الماثل

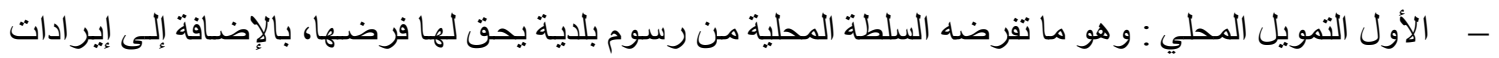

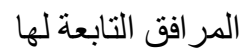

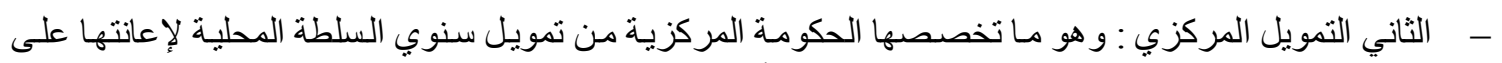

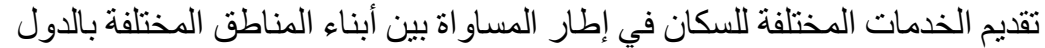

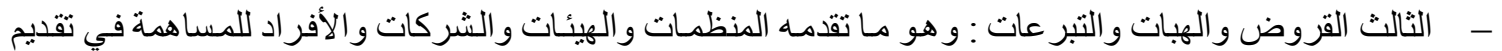
خدمات مختلفة للسكان

بو أجهزة تنفيذية لابد من وجود أجهزة تتفيذية تابعة للسلطة المحلية مباشرة تتولى تنفيذ الأعمال الموكل إلى السلطة المحلية وبجانب هذه الأجزة توجد أجهزة أخرى تابعة للحكومة المركزية تقوم بالأعمال ذات الطابع المركزي

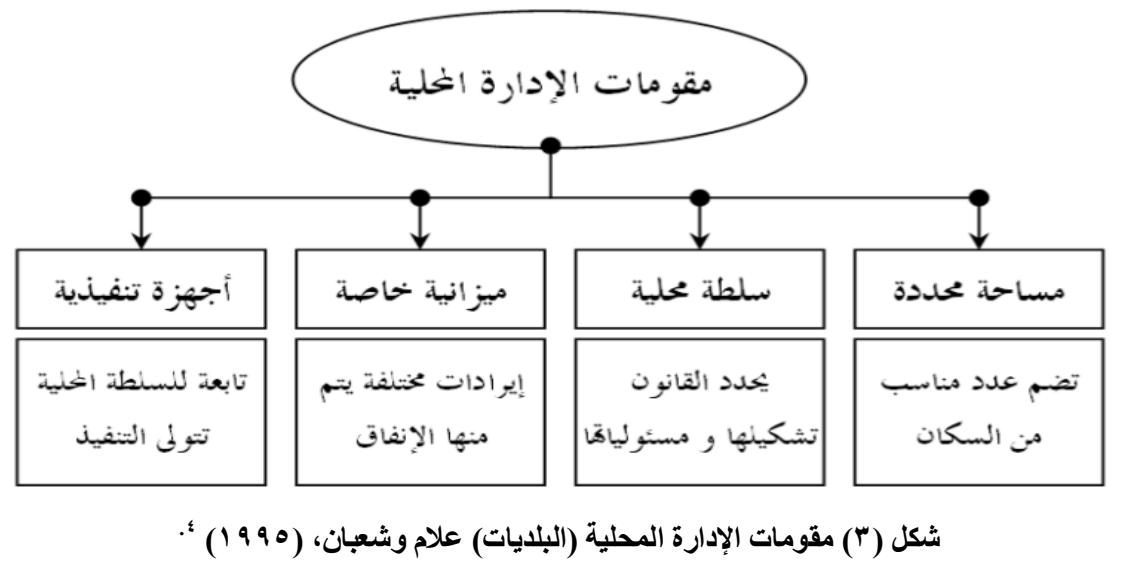




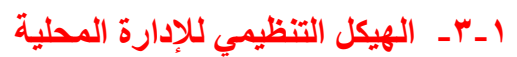

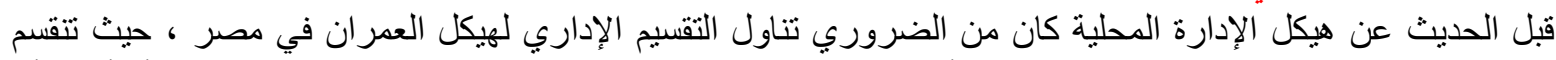

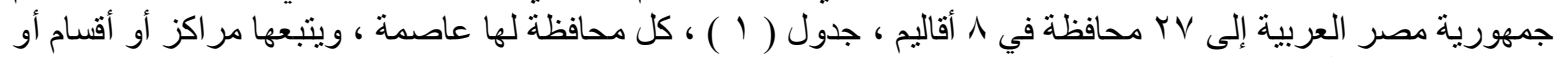

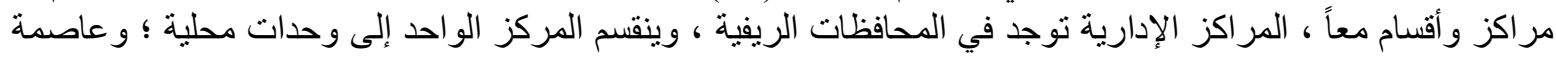

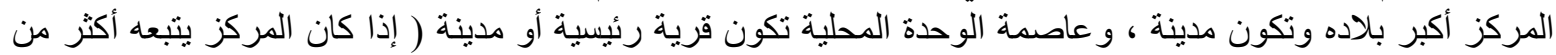

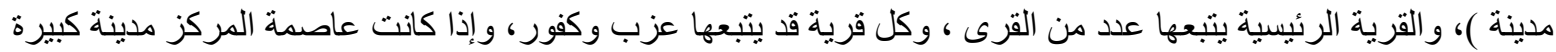

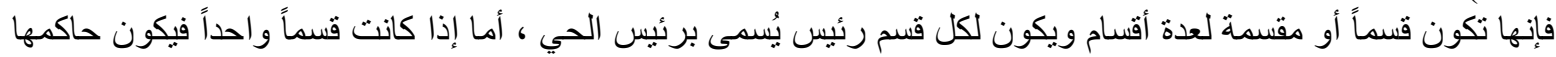

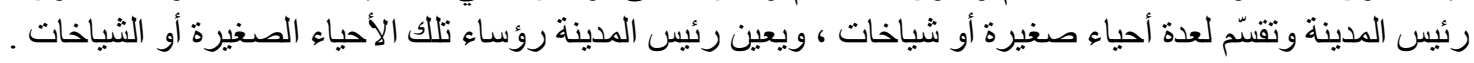

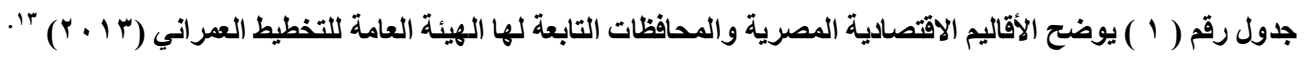

\begin{tabular}{|c|c|}
\hline المحافظات التابعة له & اسم الأقليم \\
\hline القليوبية ــ الجيزة ـ القاهرة & القاهرة الكبرى \\
\hline مطروح - البحيرة ـ الإسكندرية & إقليم الإسكندرية والمنطقة الثمالية \\
\hline دمياط ـ المنوفية ـ الغربية ـ كفر الثيخ ـ الدقهلية & 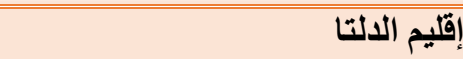 \\
\hline الثرقية ـ السويس ـ الإسماعيلية ـ البحر الاحمر - بورسعيد & 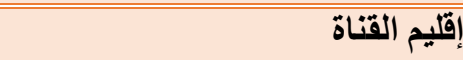 \\
\hline جنوب سيناء ـ شمال سيناء & إقليم سيناء \\
\hline الفيوم ـ المنيا - بني سويف & إقليم شمال الصعيد \\
\hline الوادي الجديد ـ أسيوط & إقليم وسط الصعيد \\
\hline أسوان - الأقصر ـ قتا ـ سوهاج & إقليم جنوب الصعيد \\
\hline
\end{tabular}

أما المحافظات الحضرية غير الريفية فتقسم إلى أقسام ، وتكون المحافظة نفسها محافظة مدينة أي تتبع سلطة المُحافظ

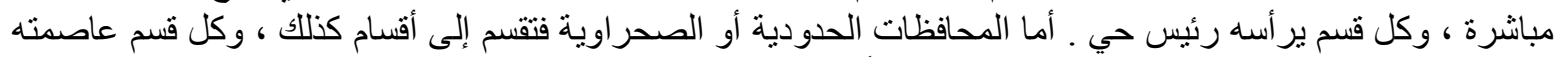

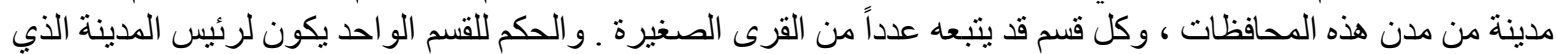

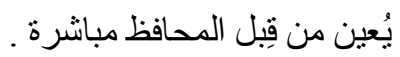

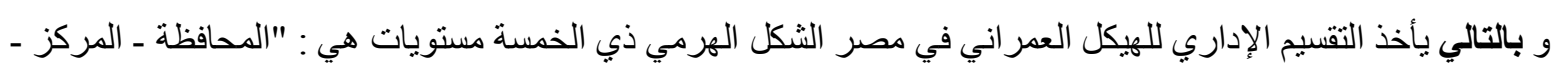

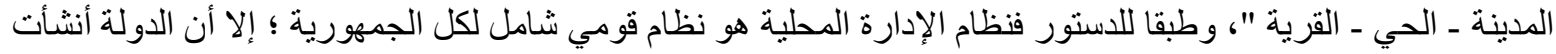

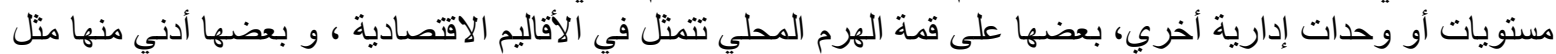

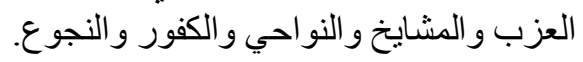

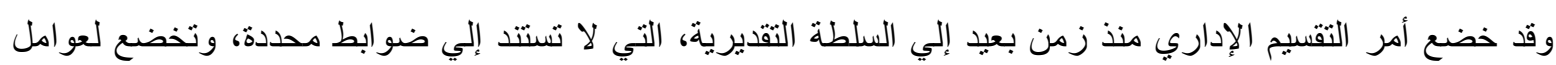

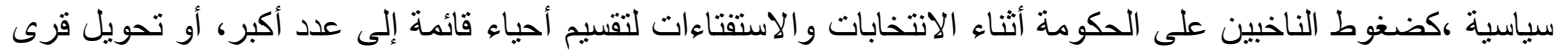

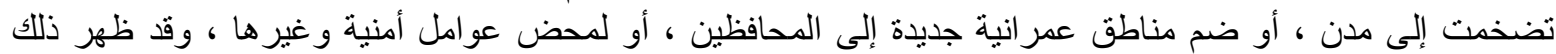

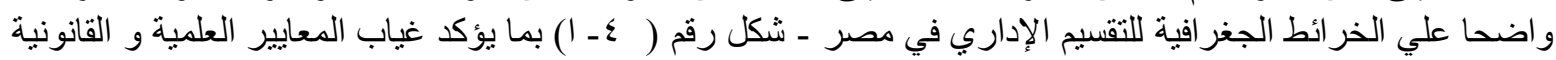

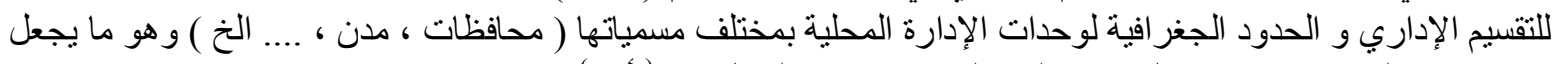

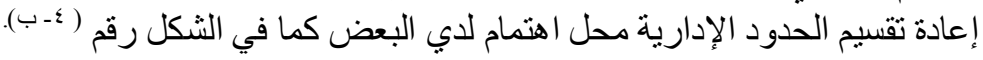



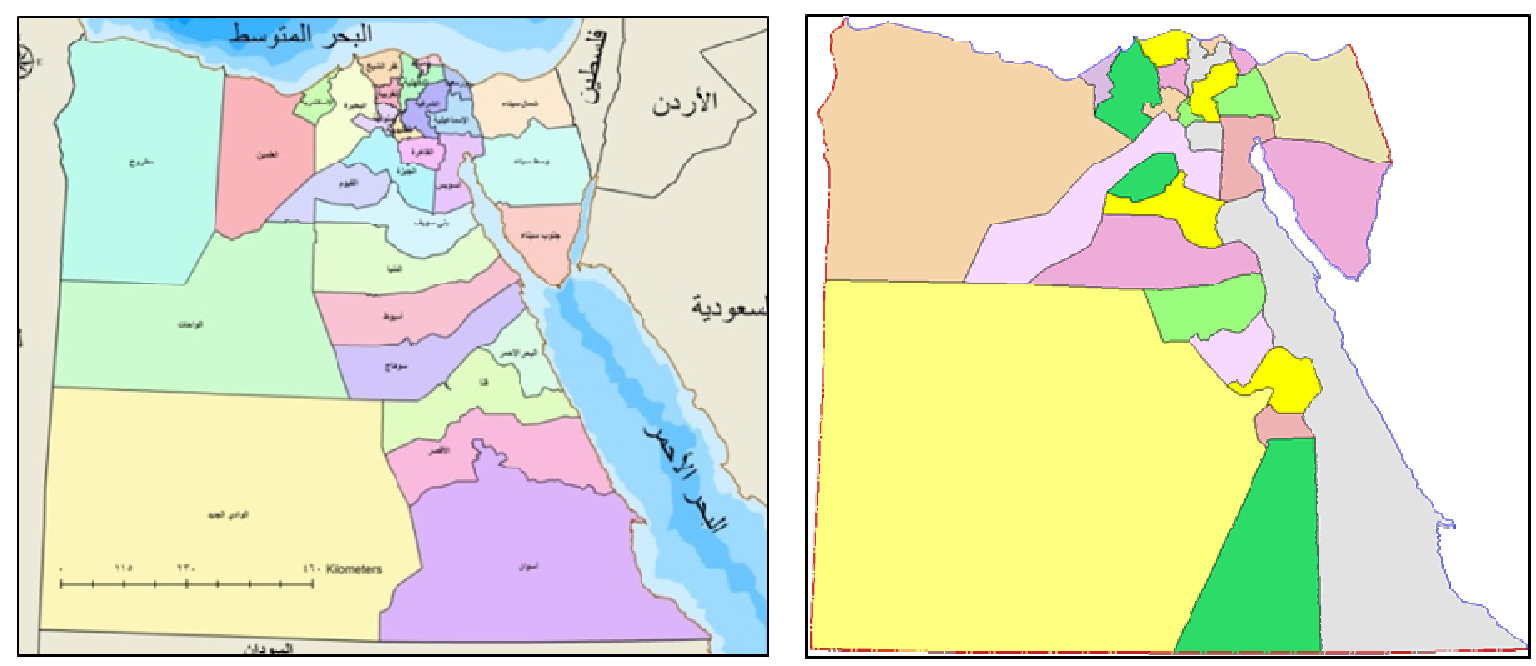

شكل رقم ( ؛ ) خريطة توضح محافظات مصر حسب التقسيم الإداري الحالي و المقترح .

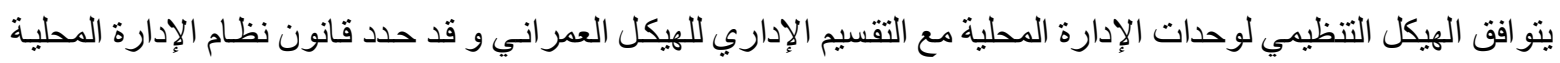

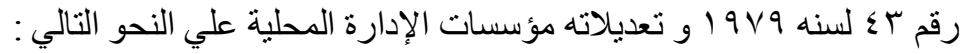

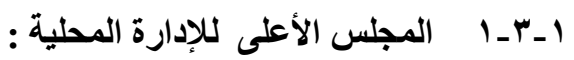

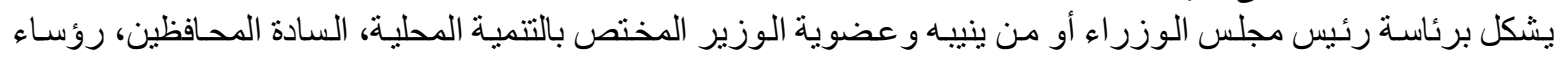

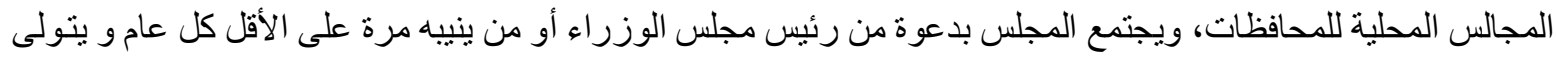

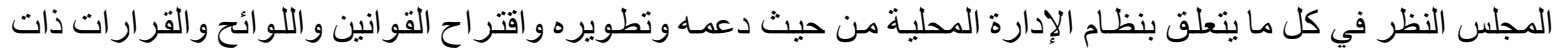

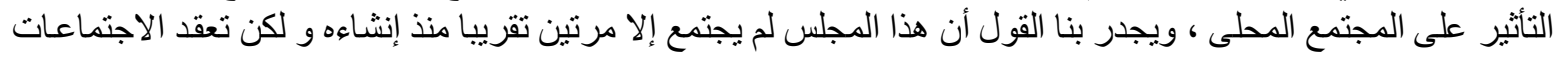

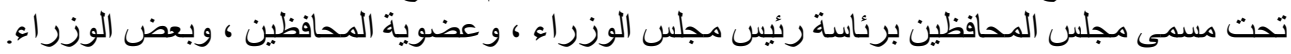

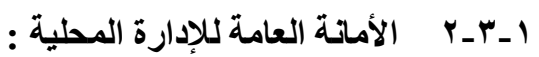

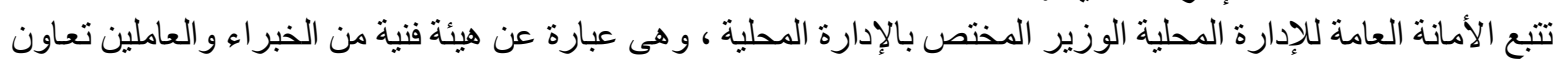

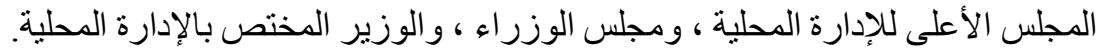

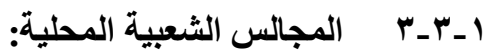

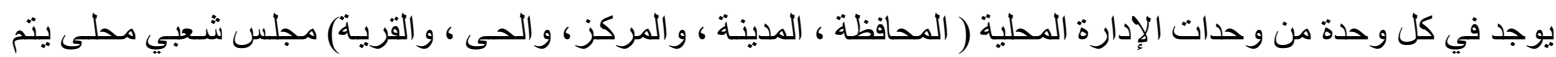

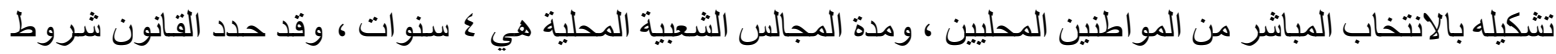
الترشح لعضوية المجالس الثعبية المحلية

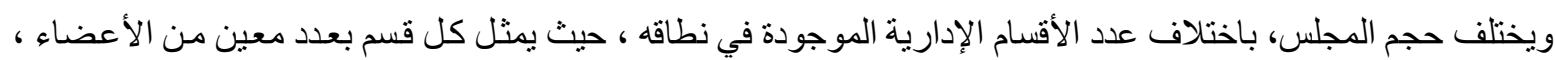

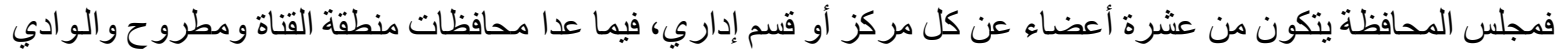

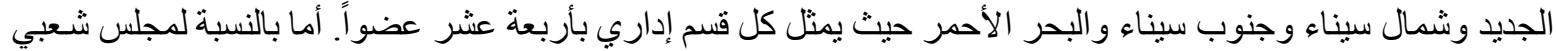

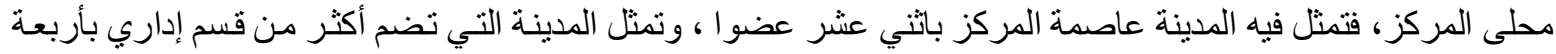

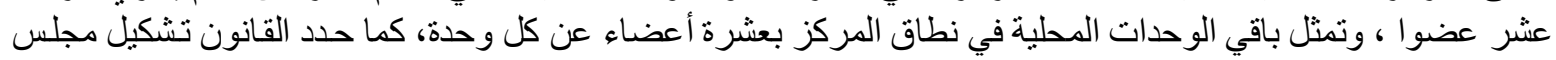

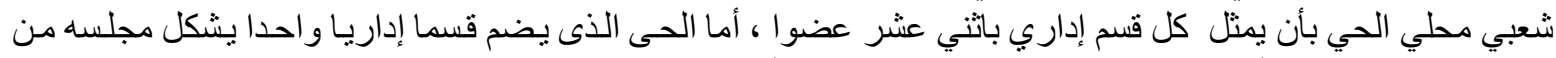

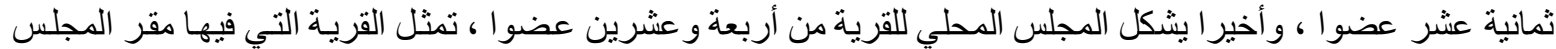

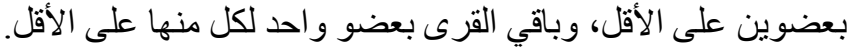

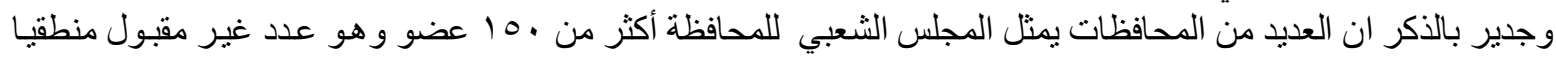
كما ان عدد مقاعد المجالس الثعبية المحلية غير مرتبط بعدد السكان في النطاق الجغر افي و الإداري للوني اللوحدة المحلية 


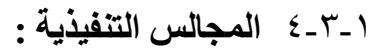

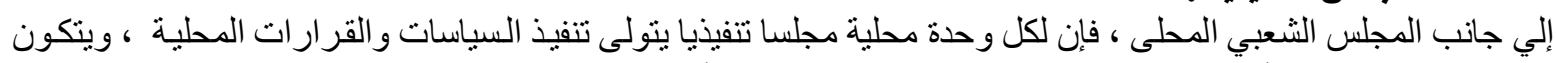

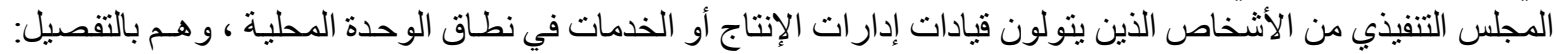

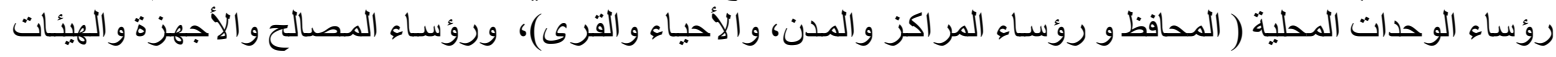

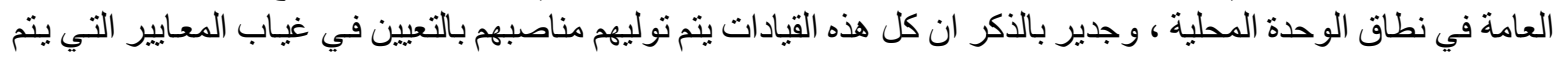
على إثر ها تعيين تللك القيادات التنفيذية المحلية.

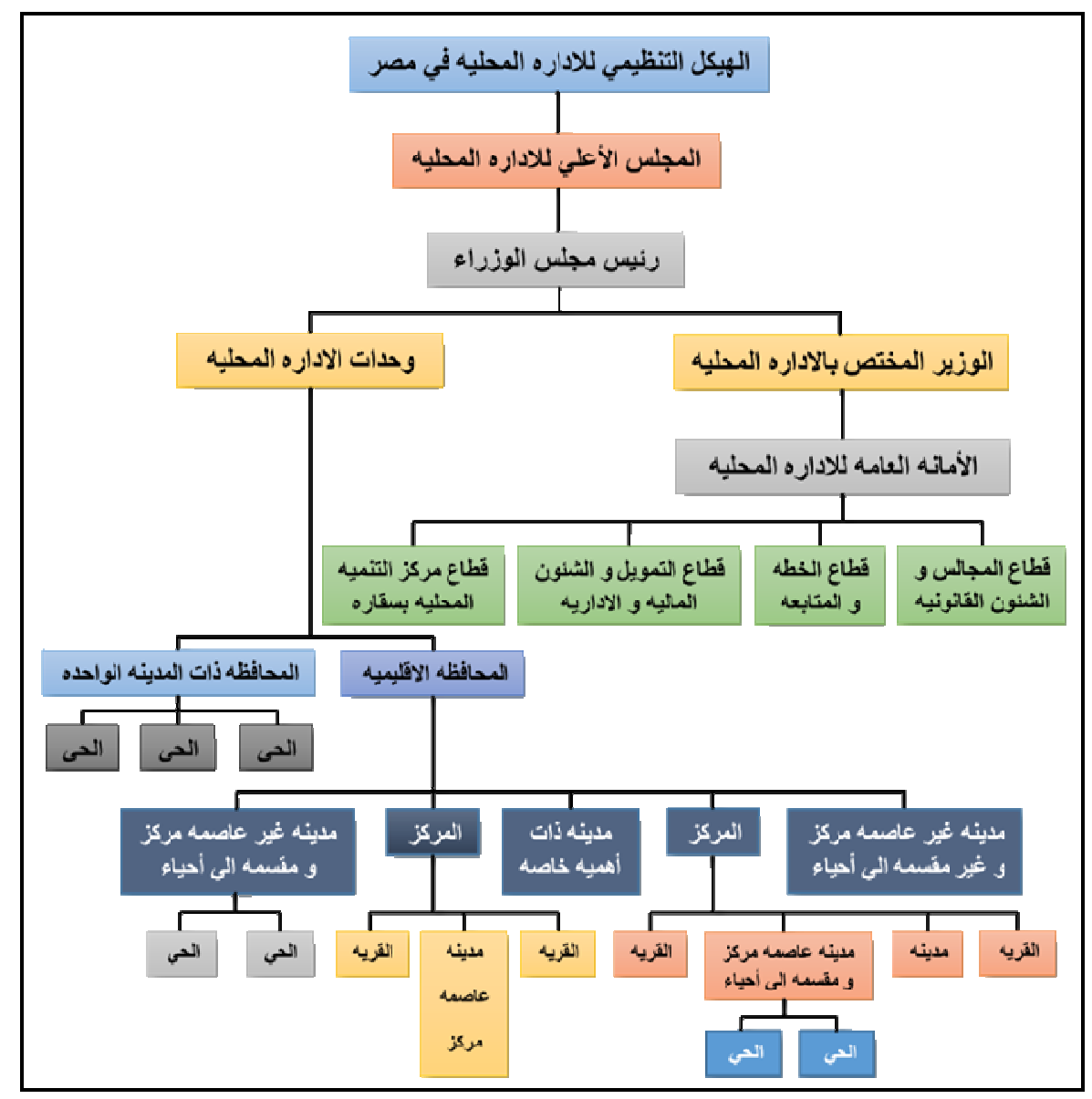

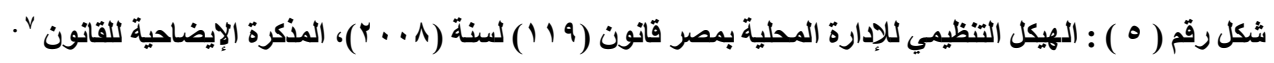

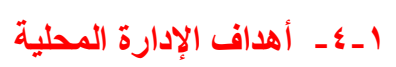

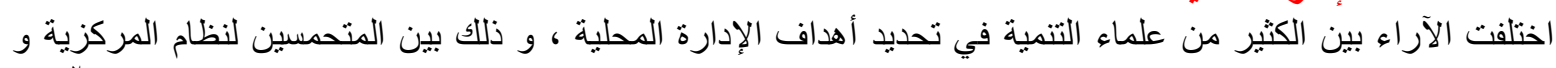

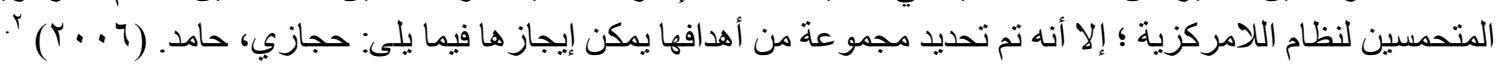

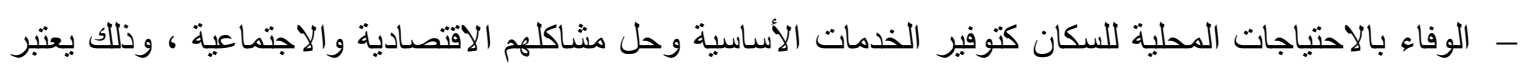

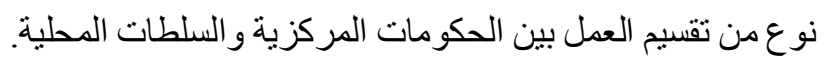

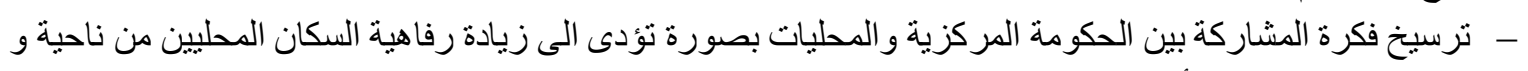
زيادة الرفاهية القومية أيضا . تئان.

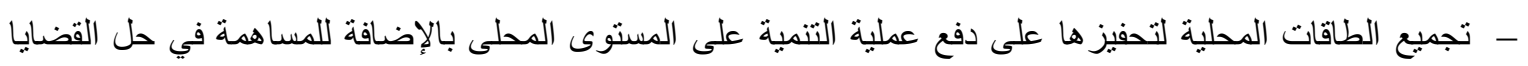

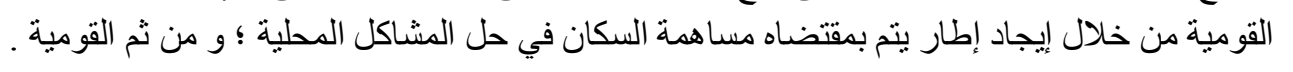




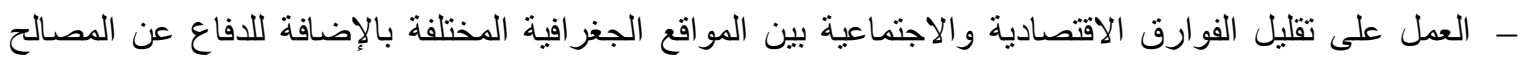

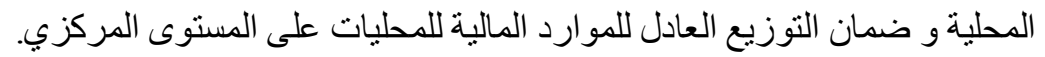

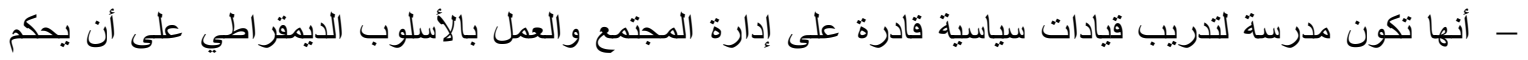

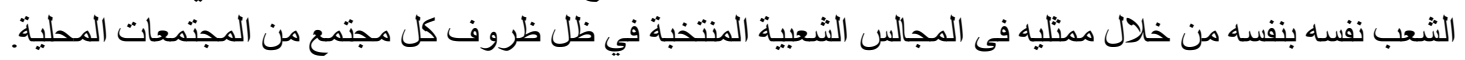

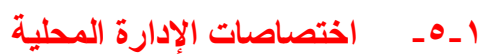

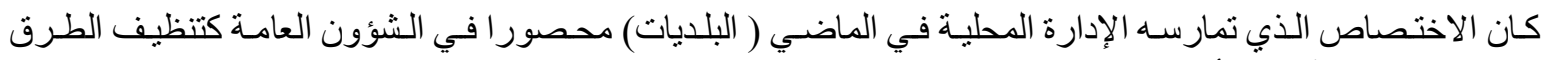

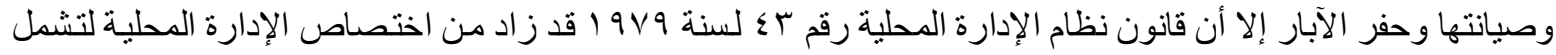
الإنشاء و التجهيز و غير ذللك.

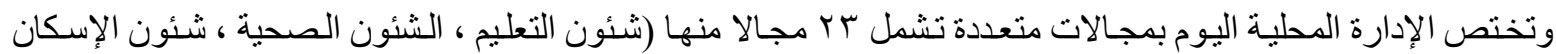

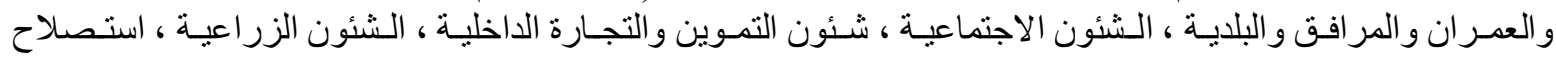

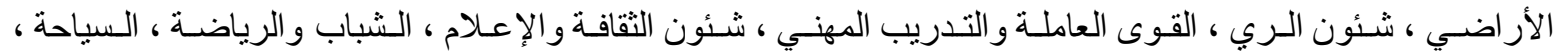

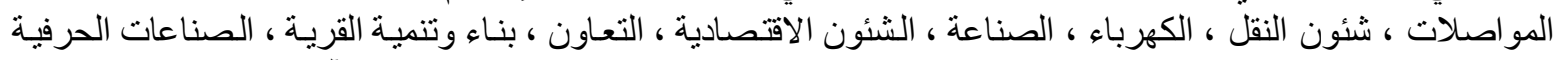

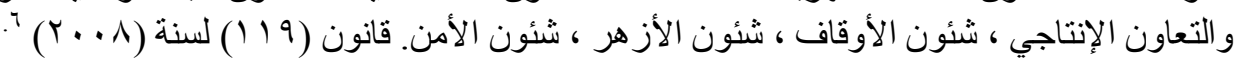

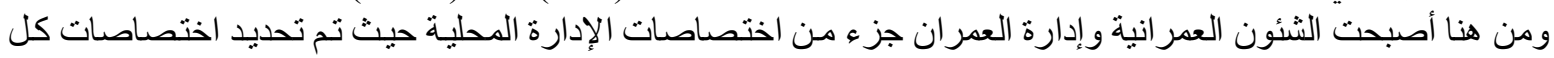

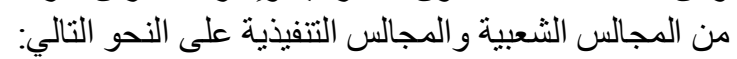

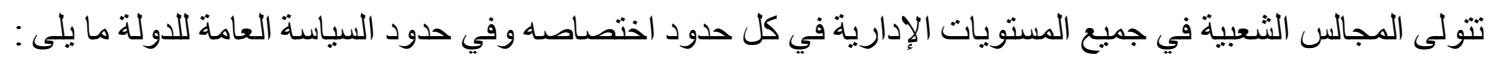

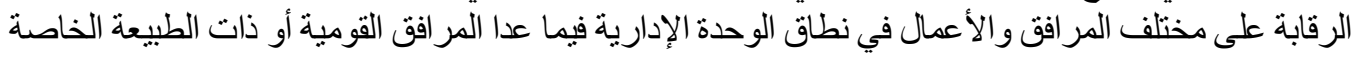

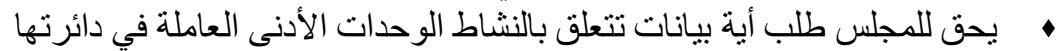

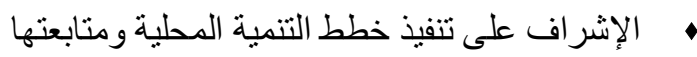

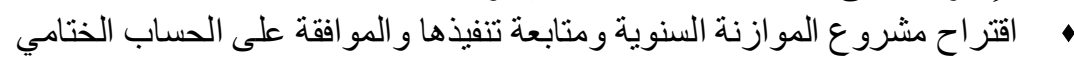

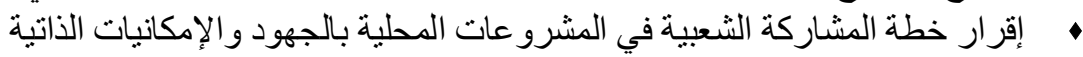

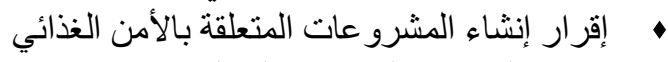

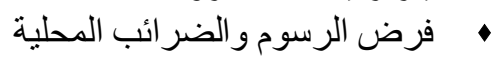

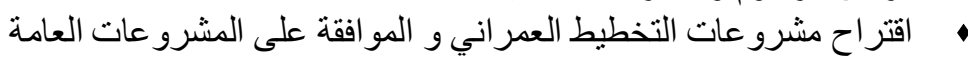

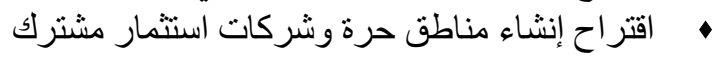

تتولى المجالس التنفيذية في جميع المستويات الإدارية كل في حدود اختصاصها وفي حدود السياسة العامة للادولة ما يلى اليى

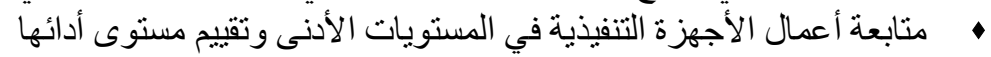

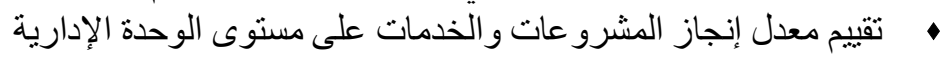

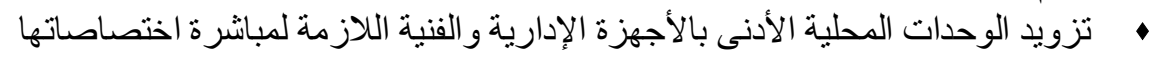

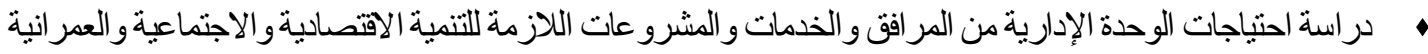

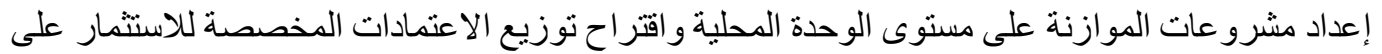

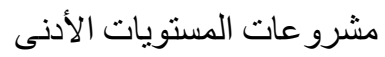

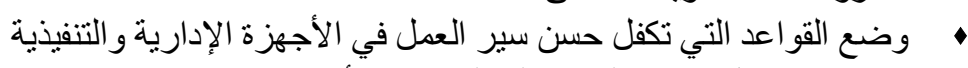

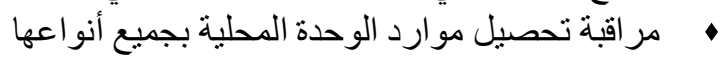

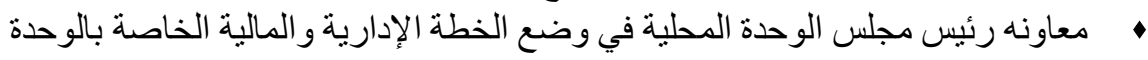

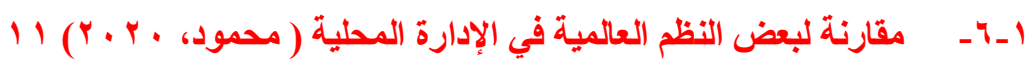

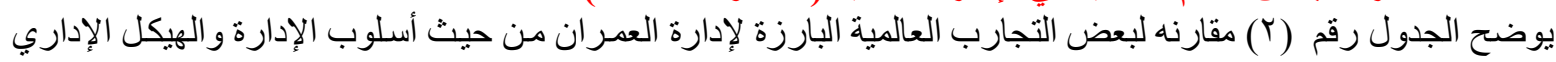

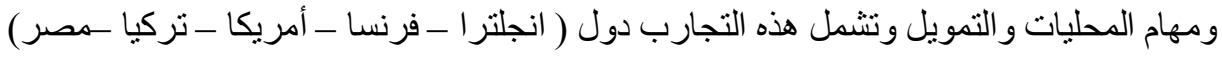




\begin{tabular}{|c|c|c|c|c|}
\hline $\begin{array}{cc}c \\
\end{array}$ & 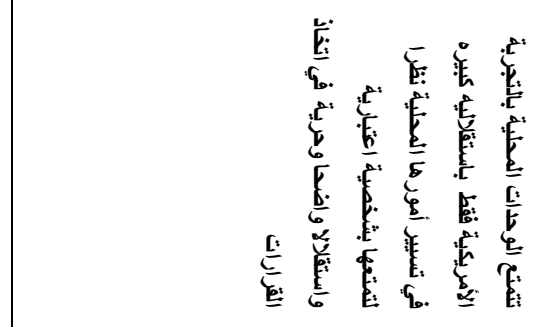 & 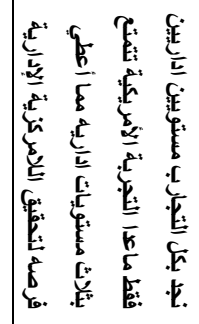 & 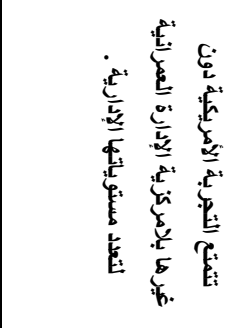 & 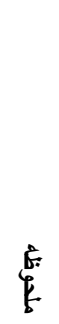 \\
\hline 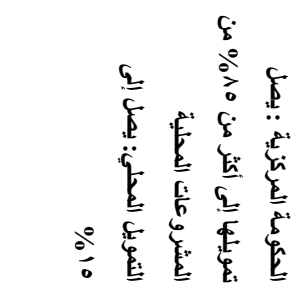 & 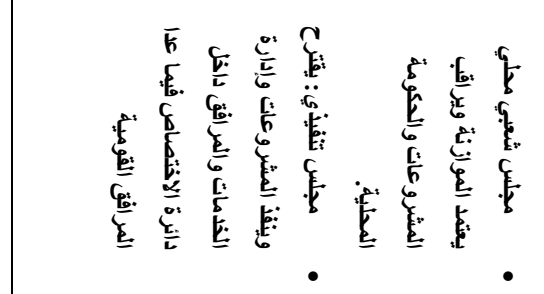 & 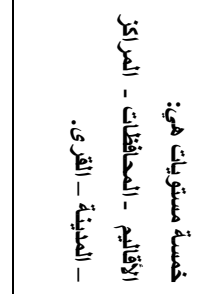 & 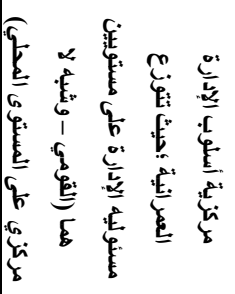 & $\frac{E}{E^{E}}$ \\
\hline 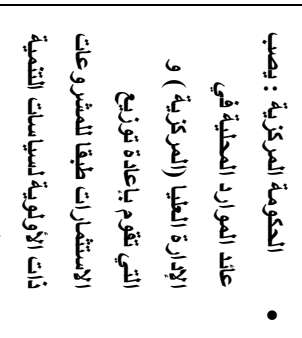 & 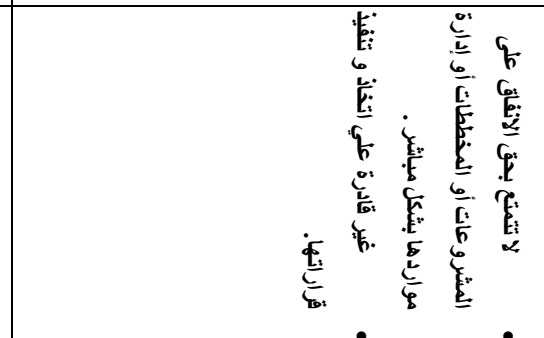 & 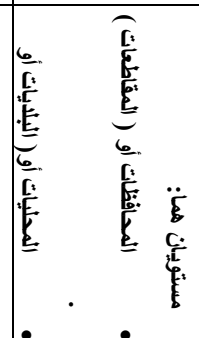 & 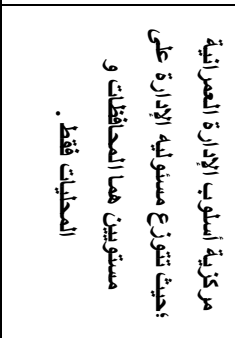 & 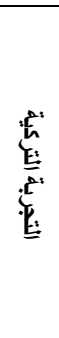 \\
\hline 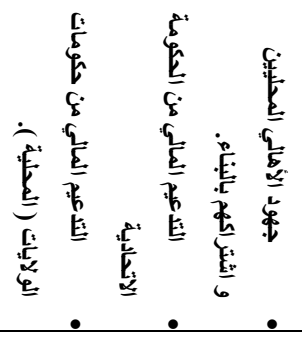 & 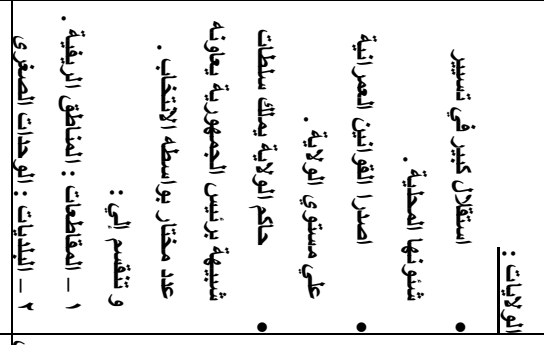 & 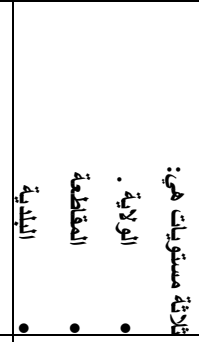 & 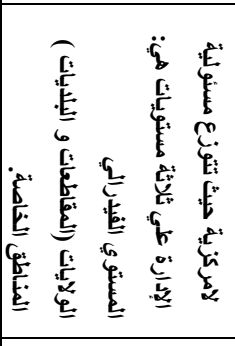 & 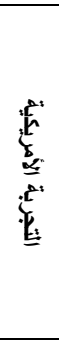 \\
\hline 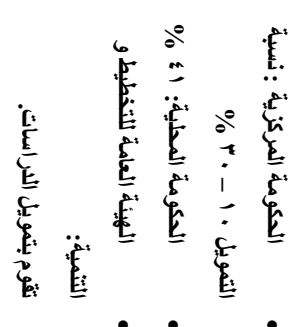 & 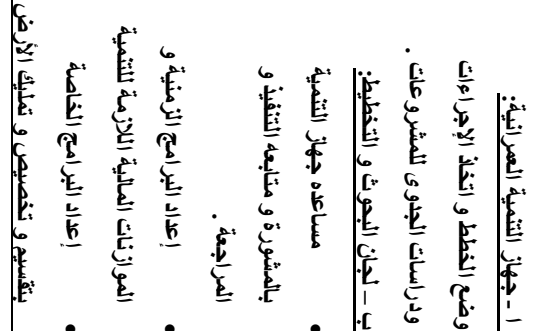 & 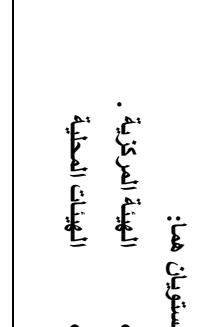 & 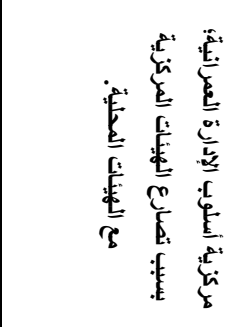 & 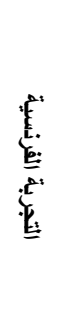 \\
\hline 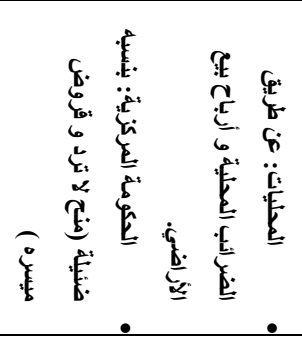 & 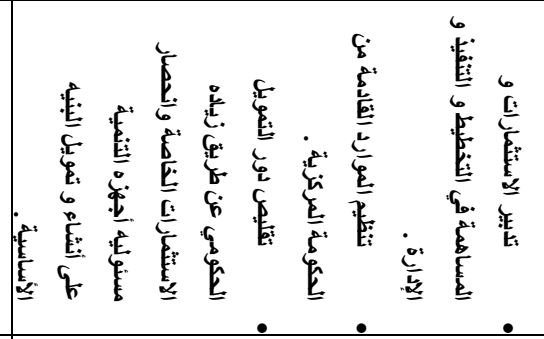 & 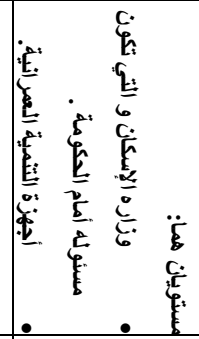 & 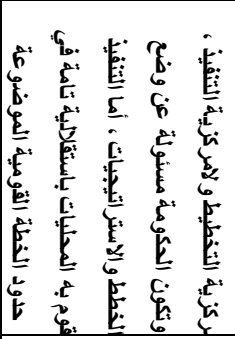 & 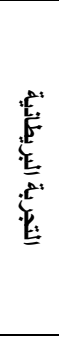 \\
\hline$\underline{\underline{E}}$ & & 点点 & $\underline{\underline{E}} \underline{\underline{E}}$ & $\frac{\delta}{5}$ \\
\hline
\end{tabular}


يتضح من الجدول السابق ان مستويات الإدارة المحلية في معظم الدول تتر اوح من مستويين الي ثلاثة مستويات في حين ان

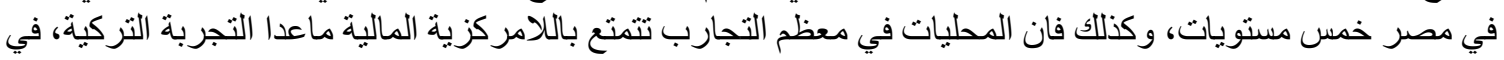

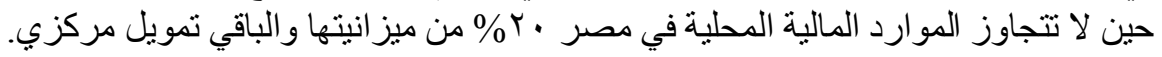

ب- ب النظم والتشريعات التي تحكم الإدارة المحلية

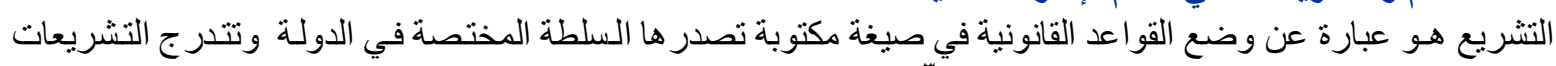

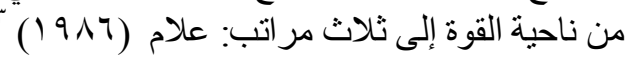
ـ الدستور : و هو التشريع الأساسي في الدولة ، وهو عبارة عنداء عن مجموعة القواعد الأساسية التي تحدد شكل الدولة وترسم نظام الحكم فيها.

ـ القانون : و هو التشريع الرئيسي الذي تصدره السلطة التشريعية ، ويتضمن كليات الأحكام للموضو عات التي يتطرق إليها

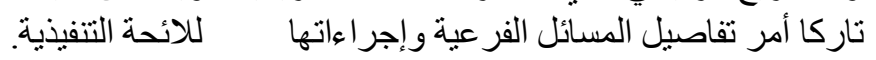

ـ اللائحة : و هي مجمو عة القو اعد التي تصدر عن السلطة التنفيذية وتوضع لتطبيق القانون وهي تثريع ثانوي يقوم بجوار

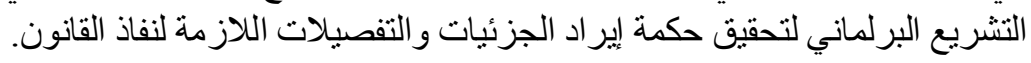

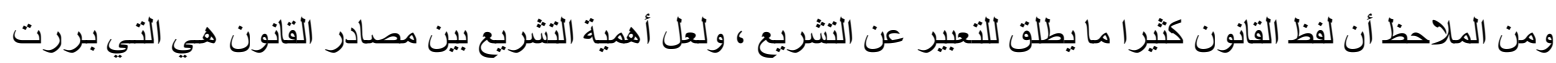

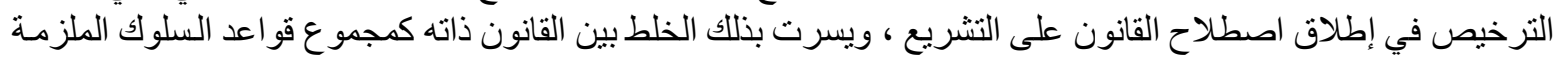

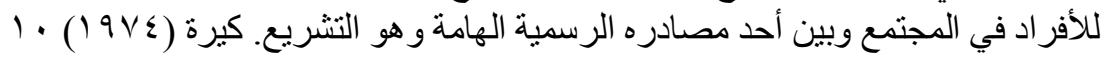

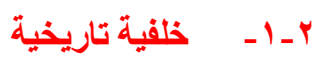

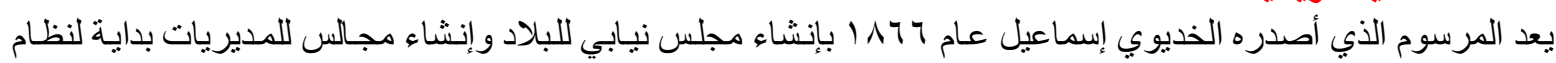

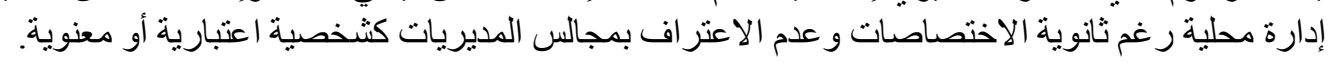

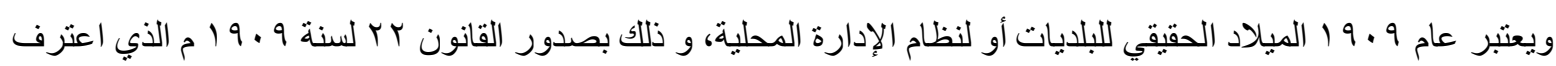

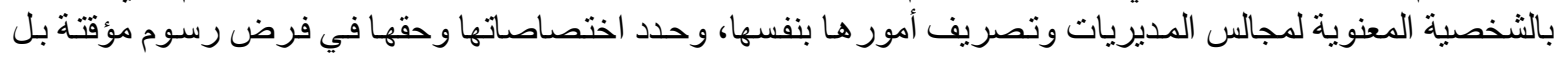
وحقها في إبداء الرأي في كل الأمور التي تهم المديرية وسكانها.

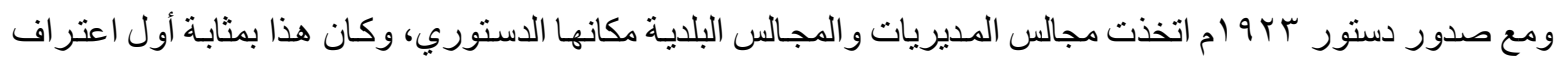

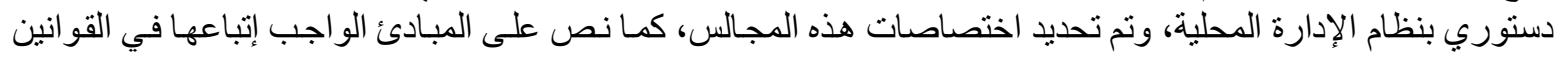

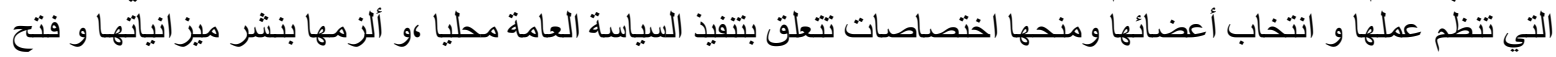
جلساتها أمام المواطنين، وكانت تلك المحطة من أهم المحطات التي تتعلق بالنظام المحلي في مصر.

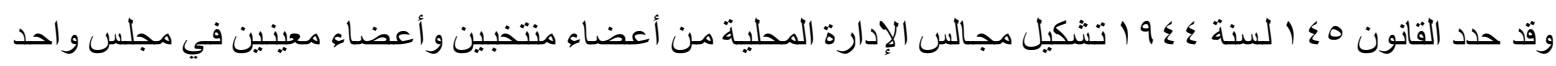

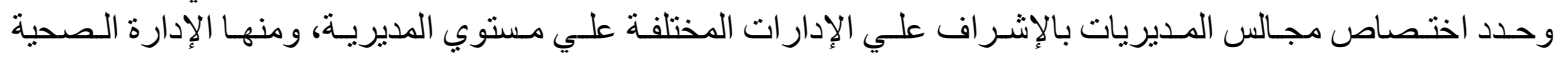

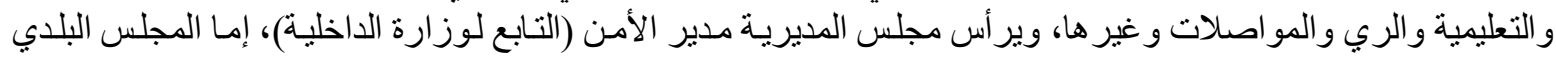

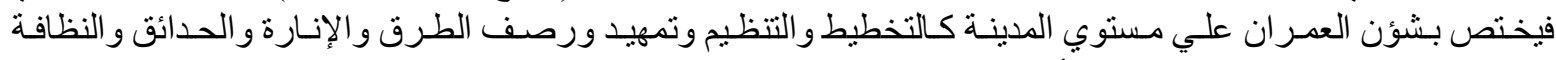
و غير ها، إما المجلس القروي فيختص بأنمال الإنتاج الزر اعي وشئون القئن القرية.

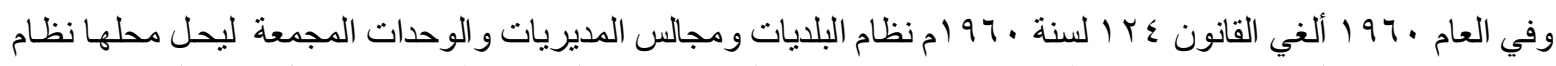

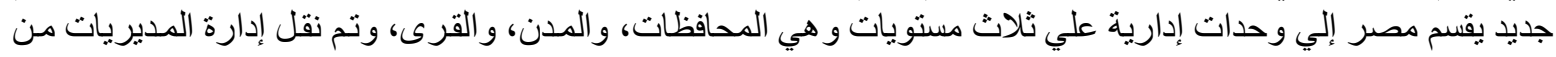

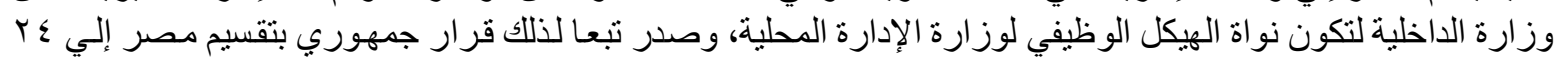

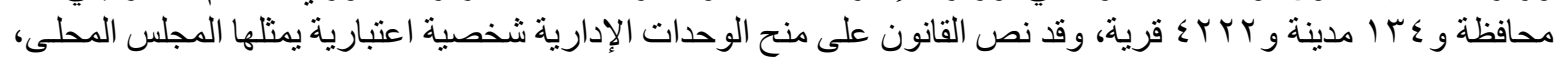

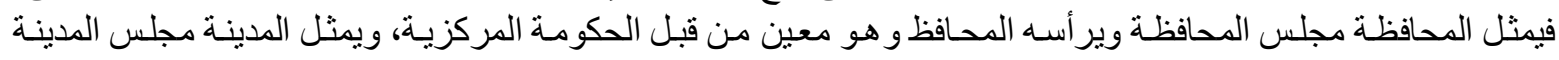

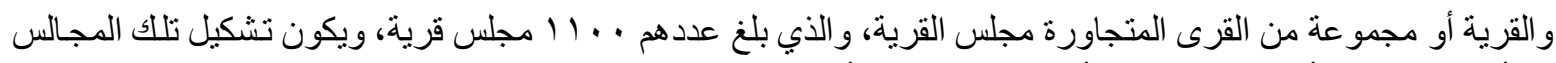

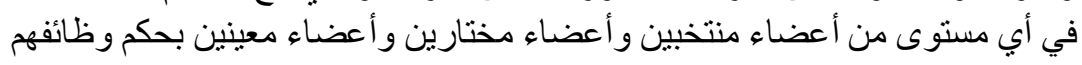

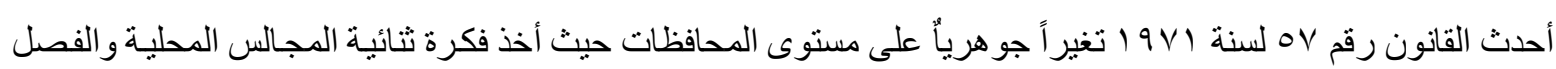

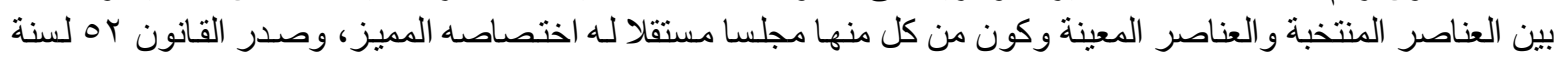


ه و أفنص على أن يكون لكل وحدة محلية مجلس شعبي يتكون من أعضاء منتخبين انتخابا مباثر ا ومجلس تتفيذي يتكون

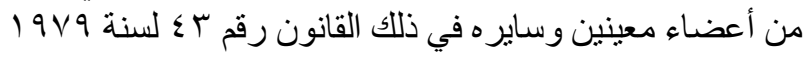

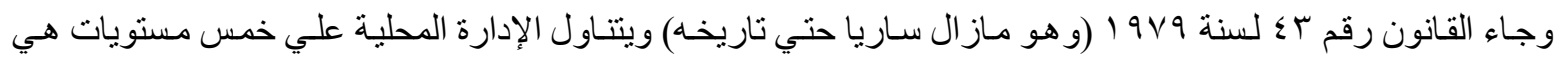

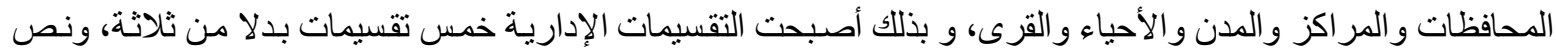

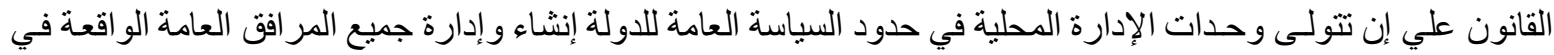

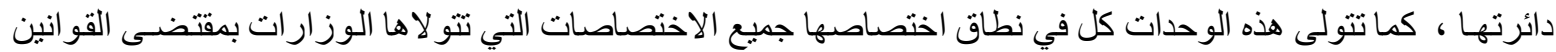

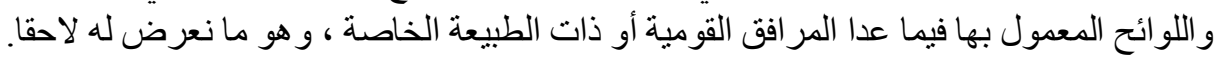

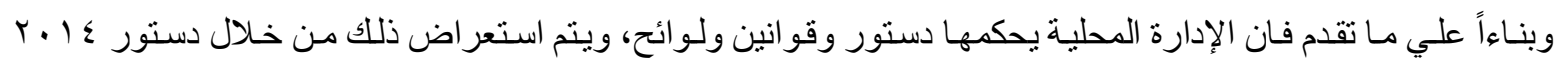

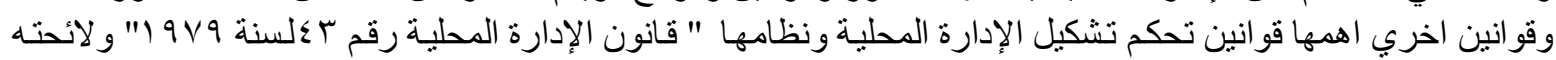

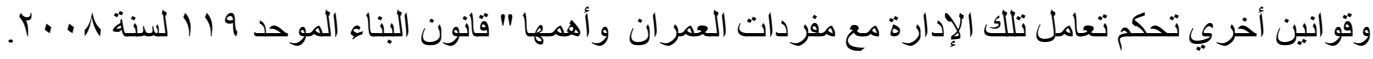

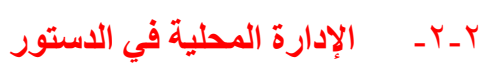

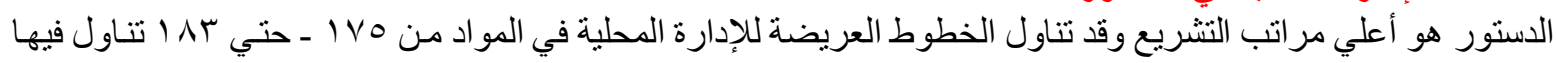

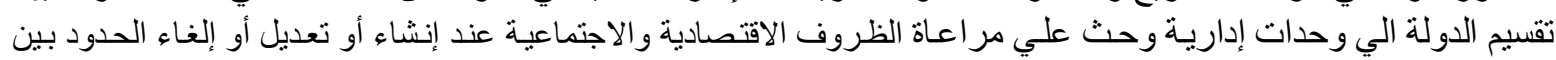

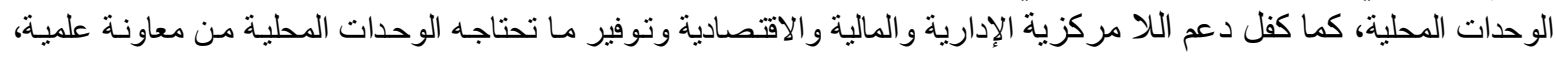

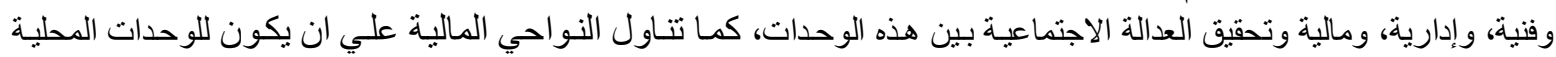

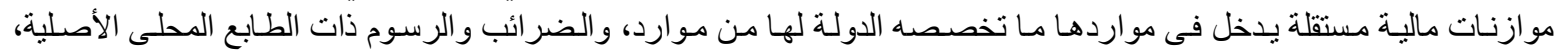

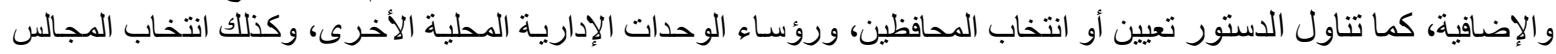

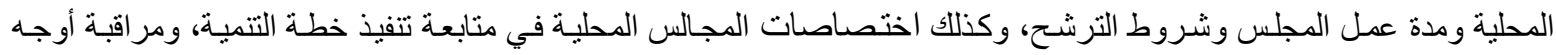

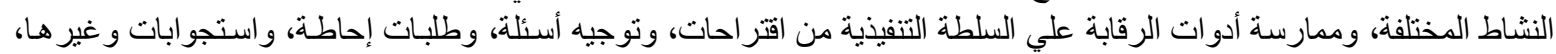

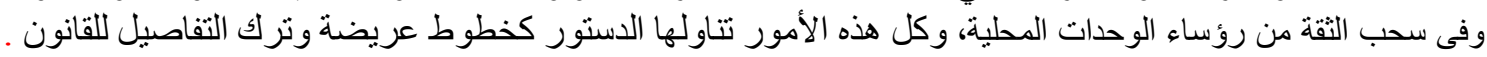

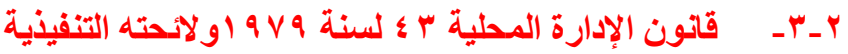

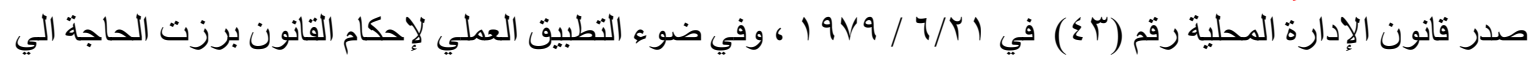

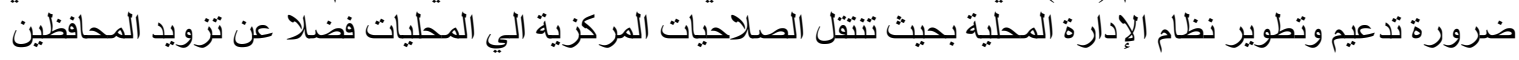

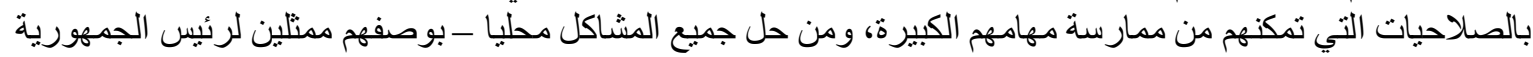

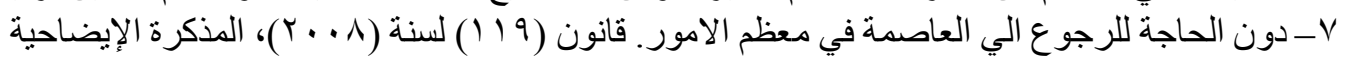

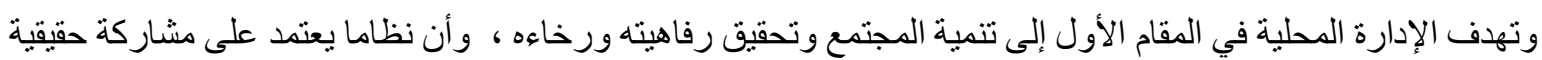

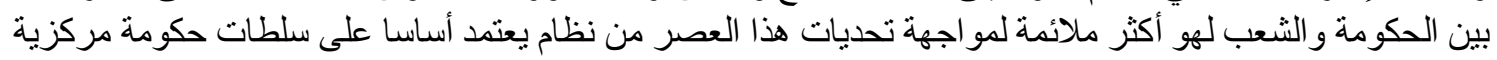

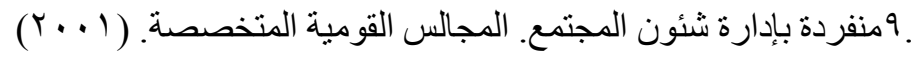

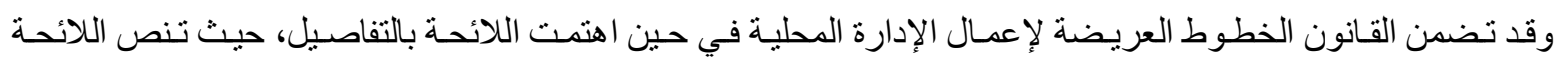

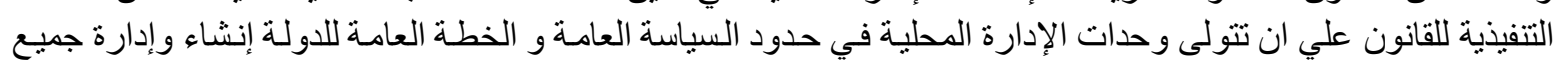

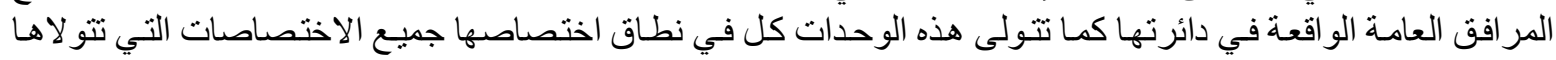

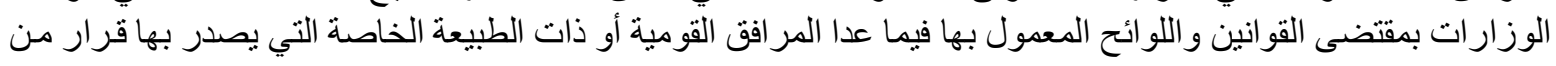
رئيس الجمهورية

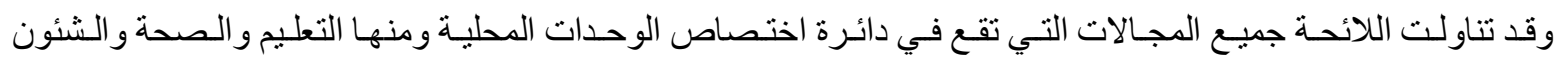

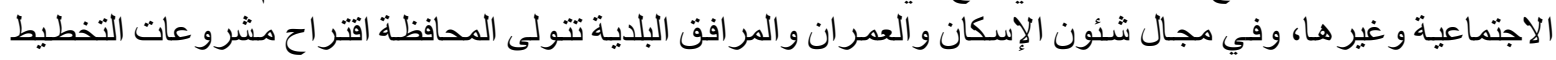

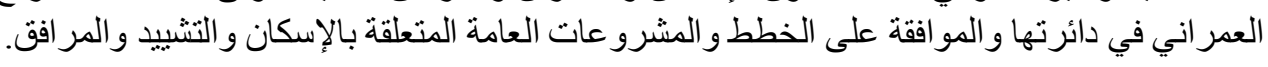
وتباشر الوحدات المحلية كل في دائرة اختصاصها الأمور الآتية :

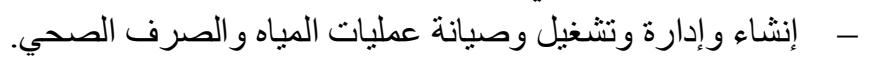

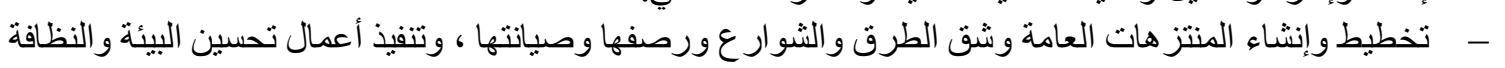

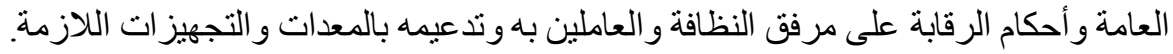
- - تنفيذ القو انين و الاشتراطات الخاصة المتعلقة بإنشاء الأسواق العامة و السلخانات و الجبانات. 
- - تطبيق القو انين والأحكام و اللو ائح المتعلقة بأعمال التنظيم وتقسيم الأر اضي و المباني وخاصـة فيما يتعلق بمطابقة

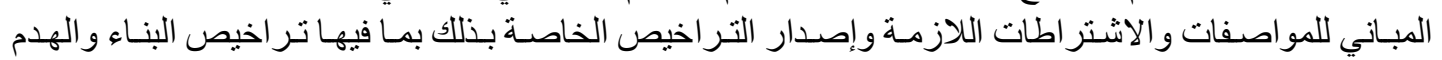

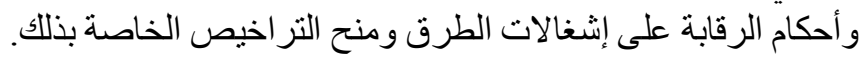

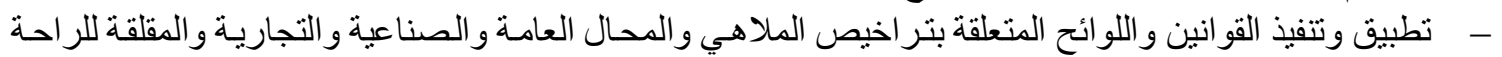
و المضرة بالصحة و الخطرة والباعة الجائلين.

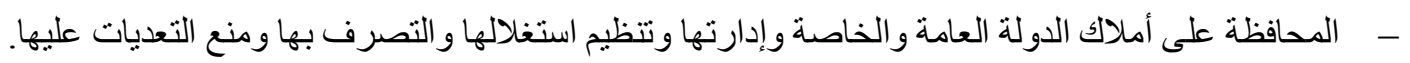

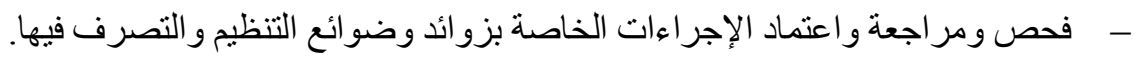

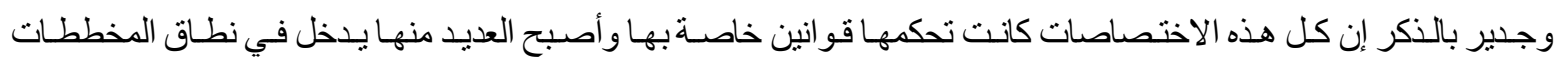

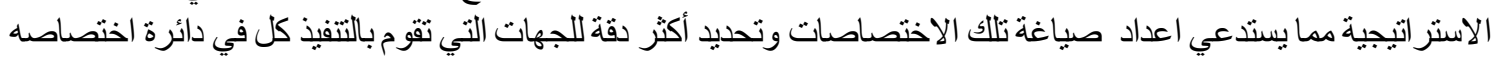

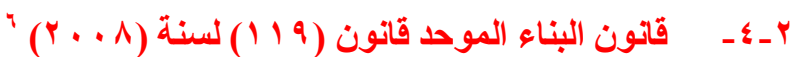

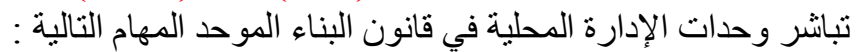

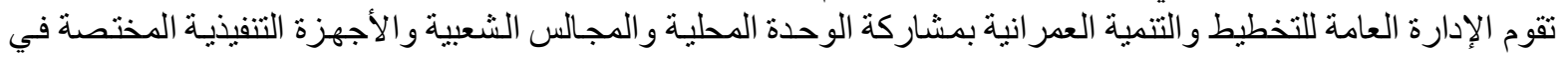

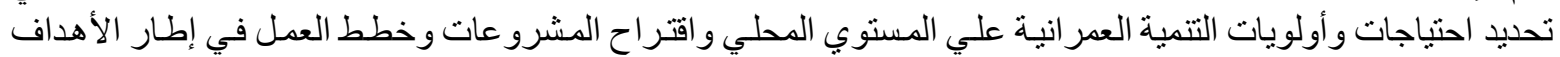

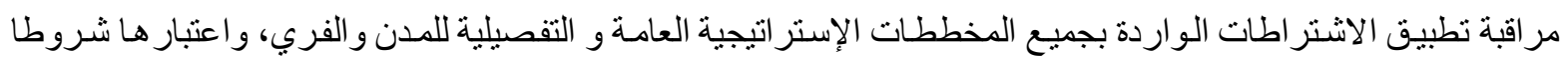

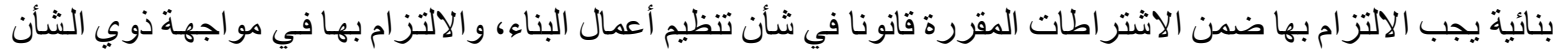

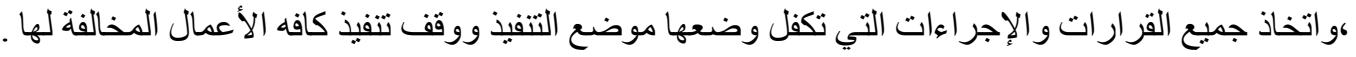

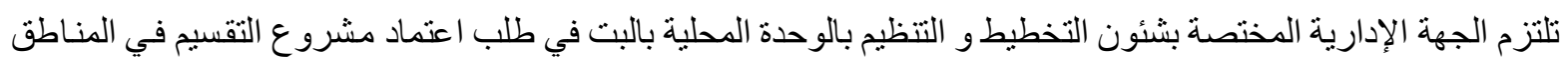

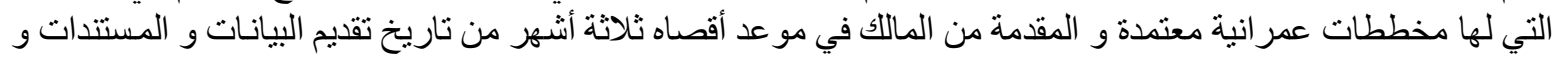
الرسومات وفقا لما تحدده اللائحة التنفيذية لهذا القانون.

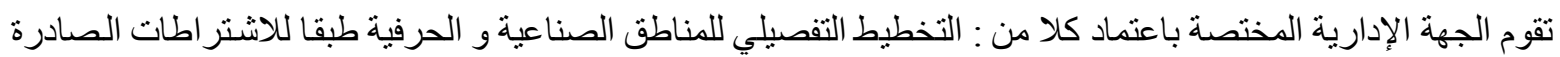

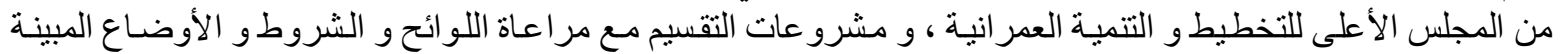
باللائحة التنفيذية لهذا القانون .

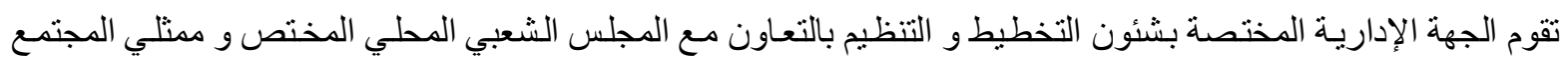

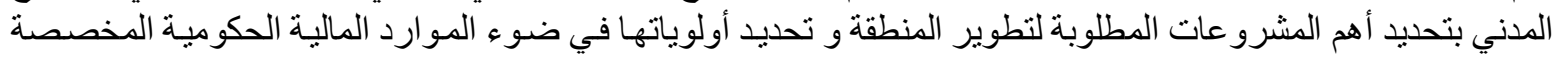

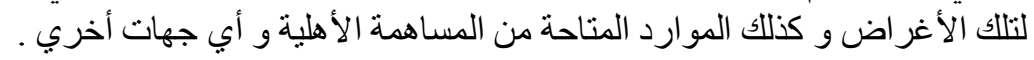

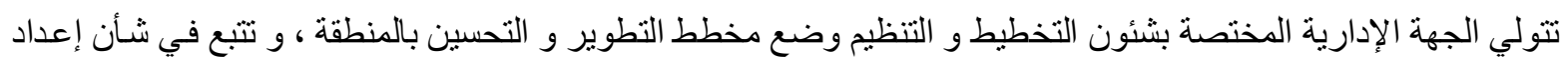

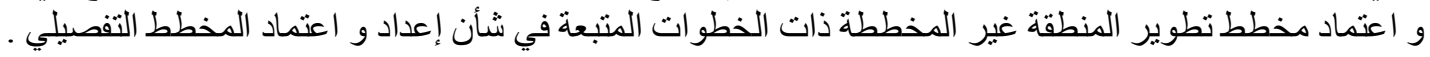

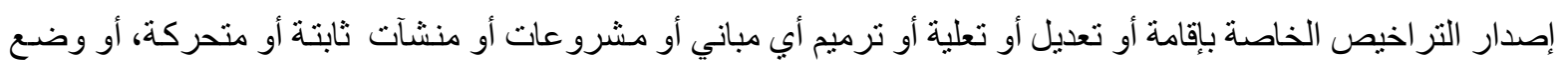

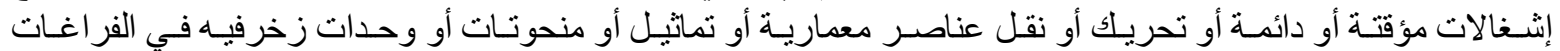
العمر انية العامة في المناطق ذاتصة القات القيمة المتميزة .

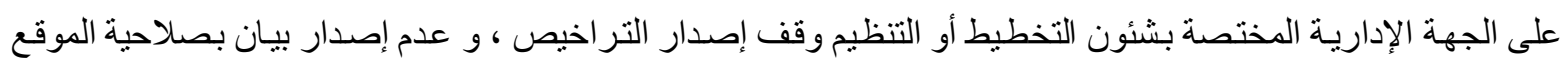

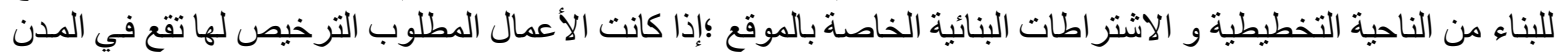

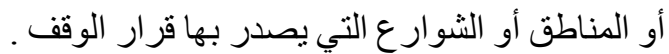

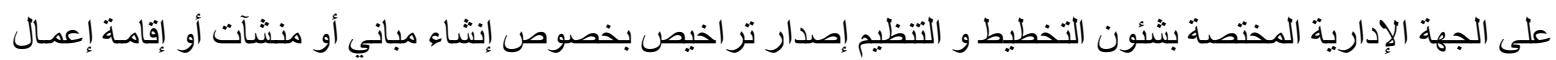

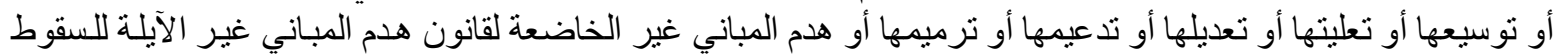

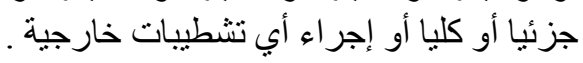

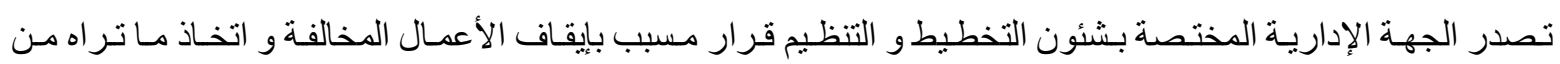
إجر اءات تكفل منع الانتفاع بالأجز اء المخالفة أو إقامة أب أعمال بناء جديدة فيها مع وضع لإن لافتة تفيد ذللك . 


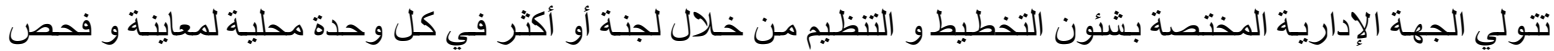

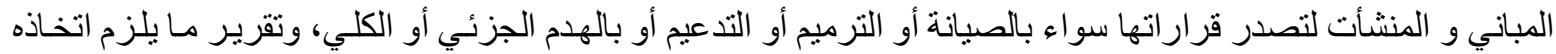

للمحافظة على الأرواح و الأموال. تلندان.

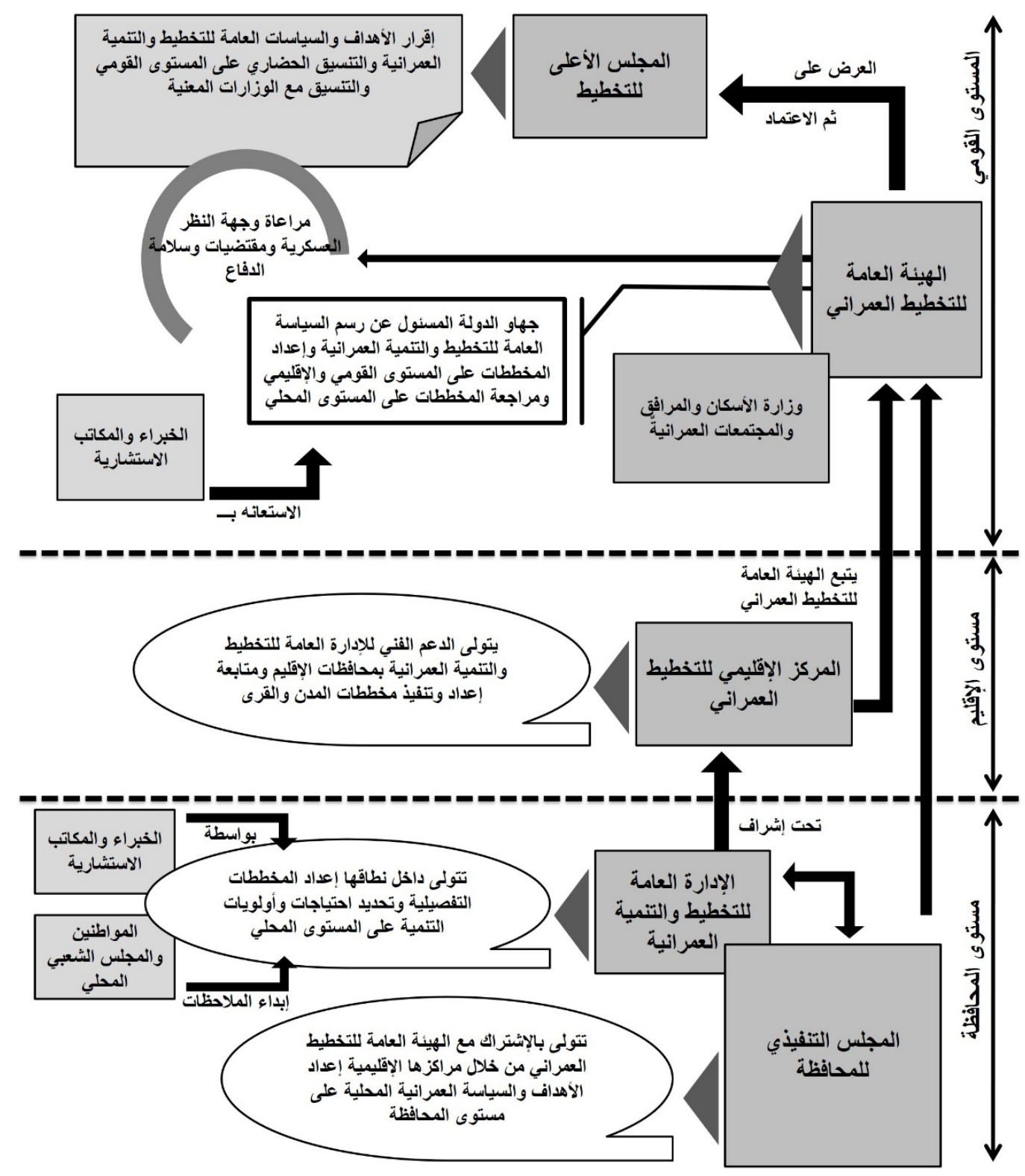

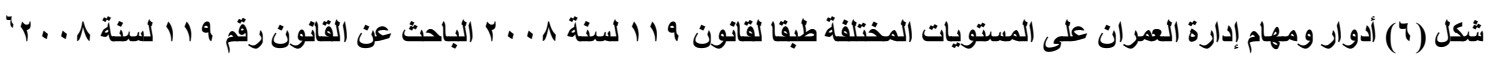

بـ التمويل المخصص لإدارة العمران

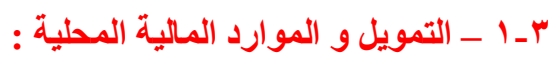

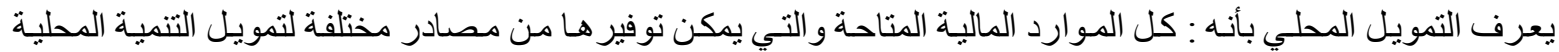

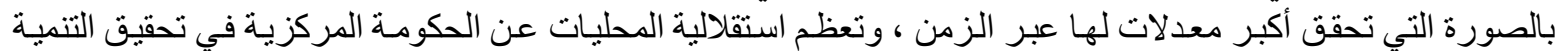

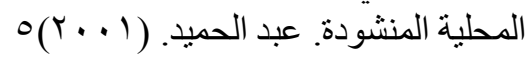
ويشترط في التمويل المحلي (محليه المورد - ذاتيه المورد - سهوله أداره المورد - مرونة المورد ـ كفاية واتساع المورد. ) 


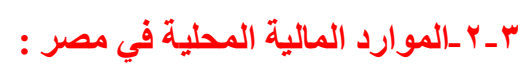

تنقسم مصادر التمويل بمصر إلى موارد خاصة فية ومو ارد أخرى مشتركة، وهما كالتالي :

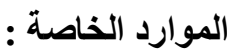

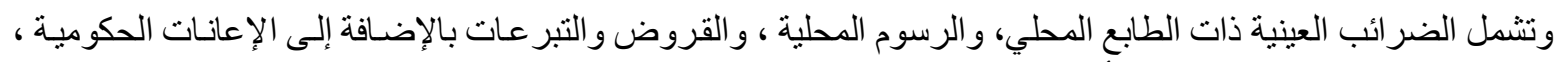

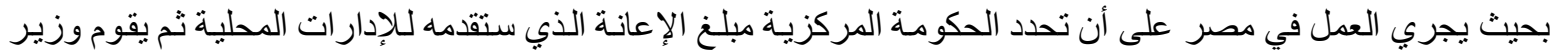

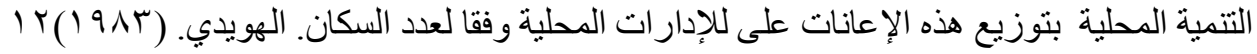

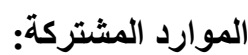

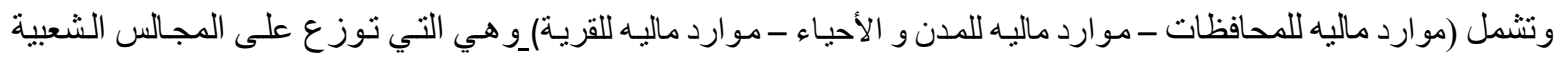

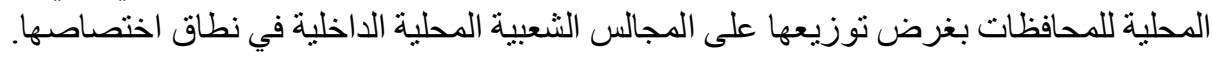

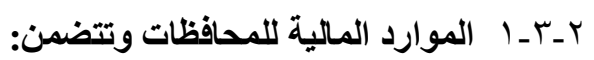

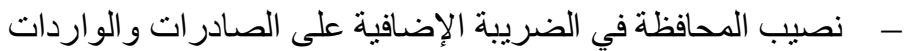

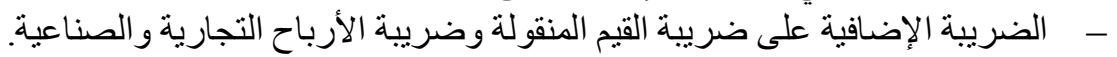

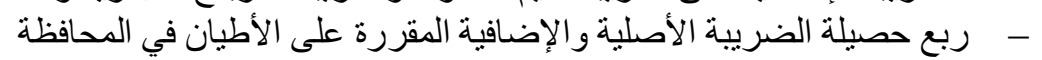

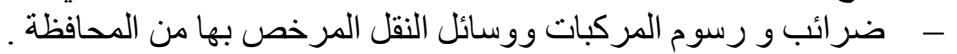

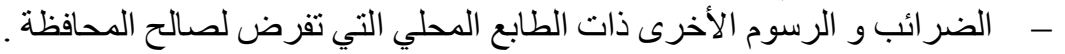

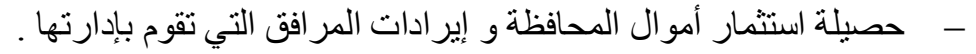

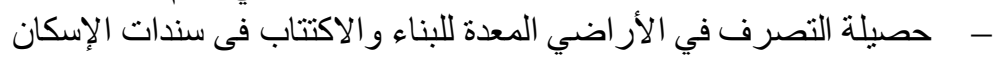

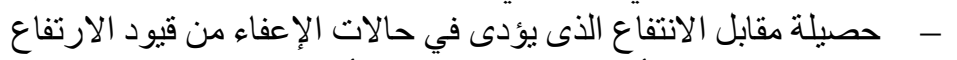

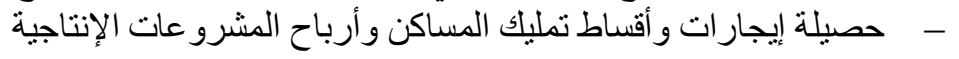

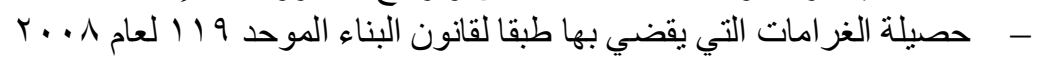

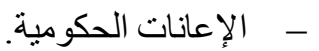

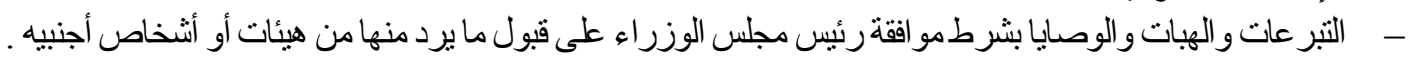

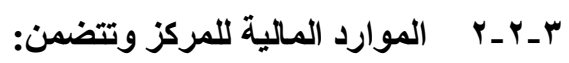

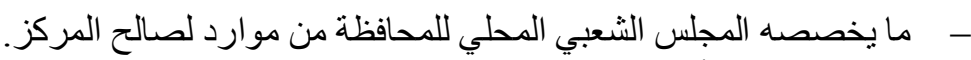

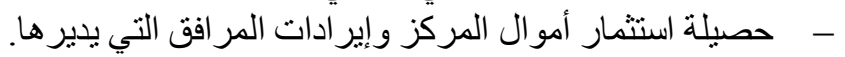

- - القروض التي يعقدها المجلس الثعبي المحلي للمحافظة.

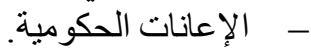

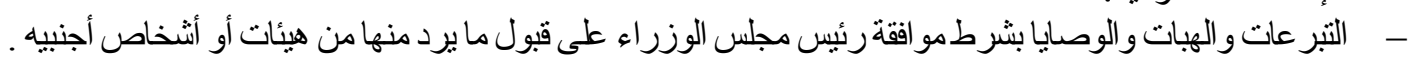

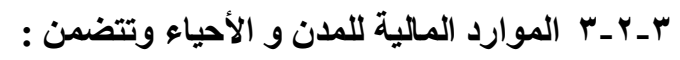

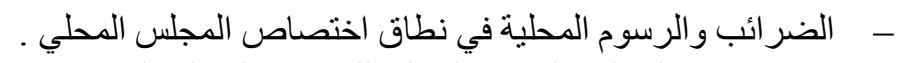

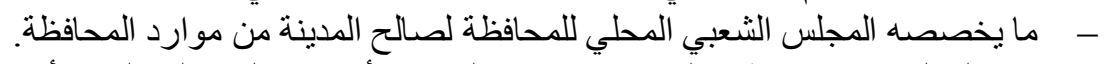

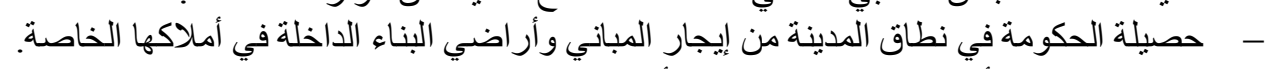

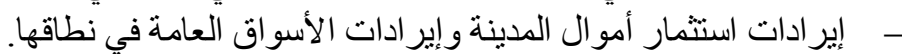

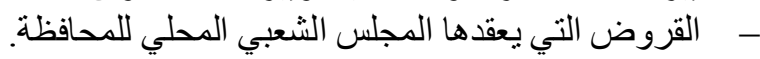

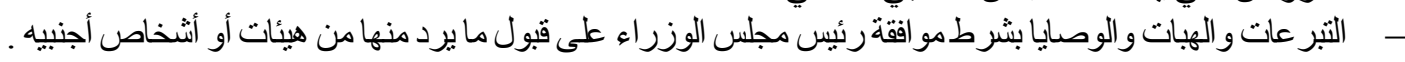

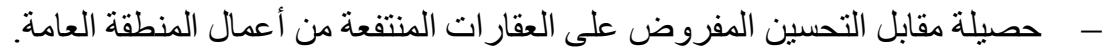

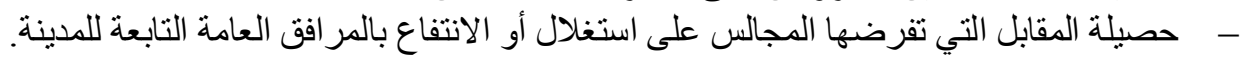

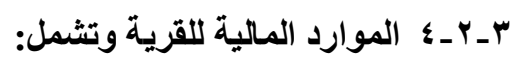

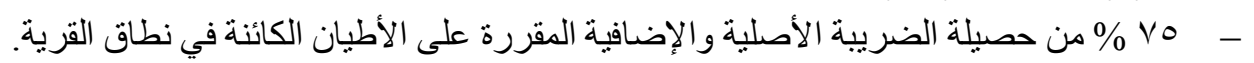

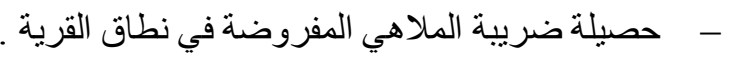

- - مو ارد أمو ال القرية و المر افق التي تقوم بإدارتها. - - القروض التي يعقدها المجلس الشعبي المحلي للمحافظة. 


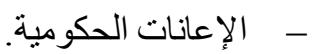

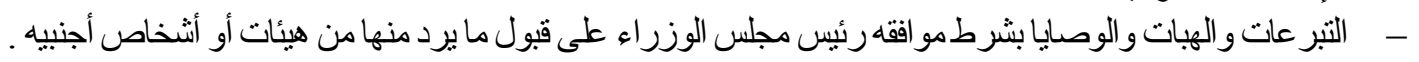

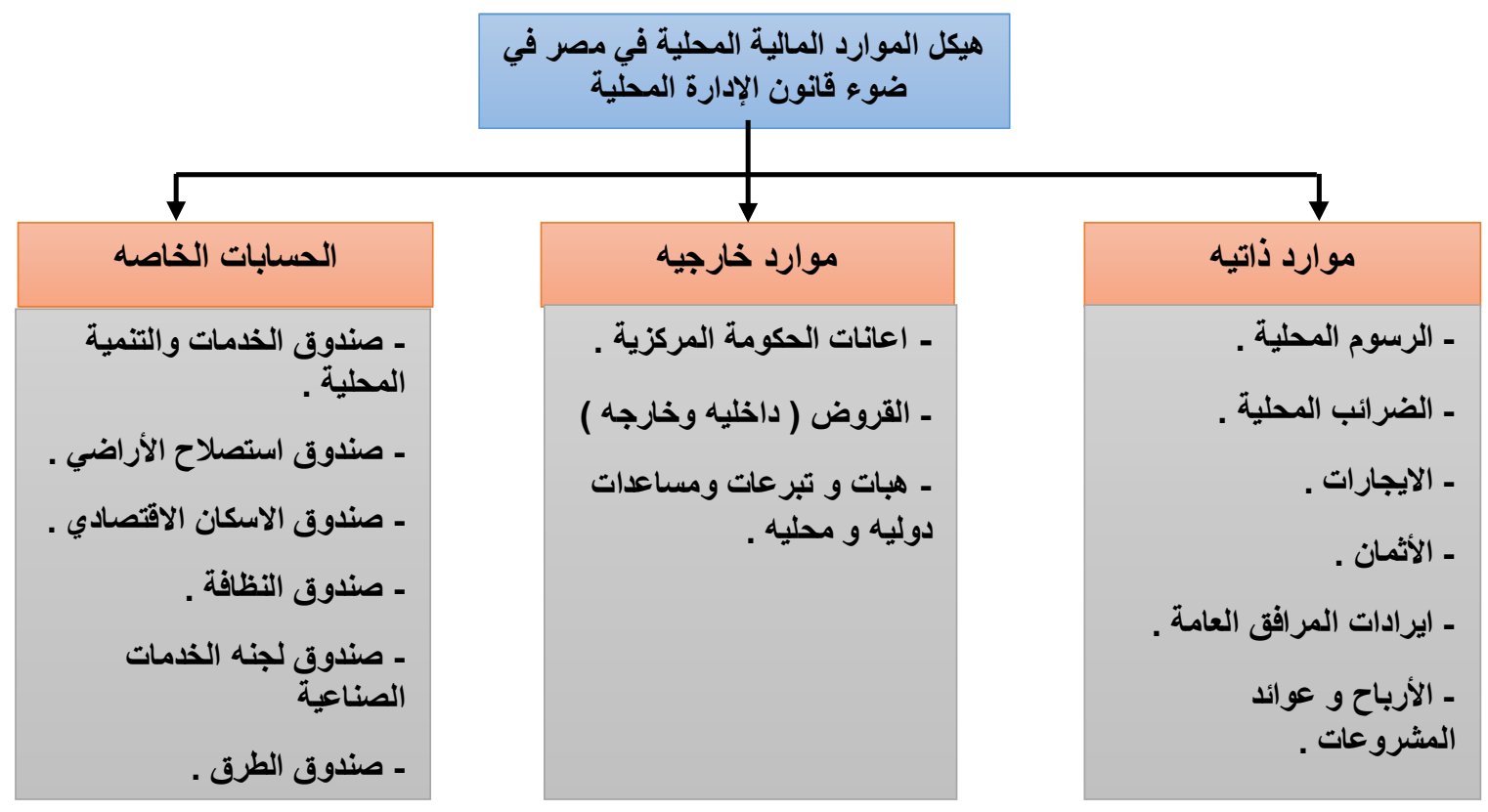

شكل ( V ) : الموارد المالية للمحليات في مصر

و عند فحص هذه المو ارد المحلية علي ارض الواقع .. يتضح عدم كفاية هذه المو ارد لتغطية احتياجات المدن و مـا يتبعها من

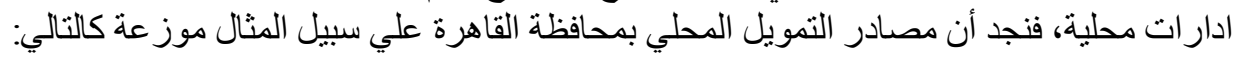

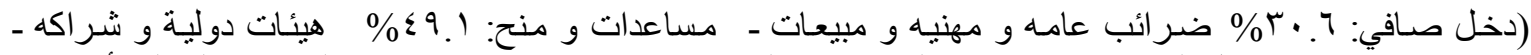

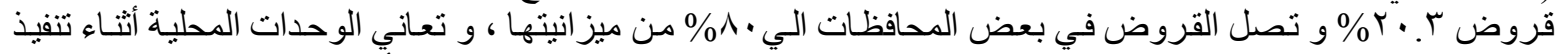

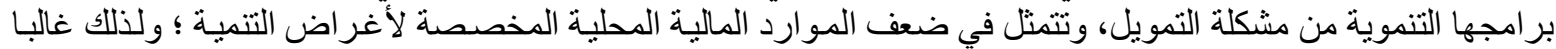

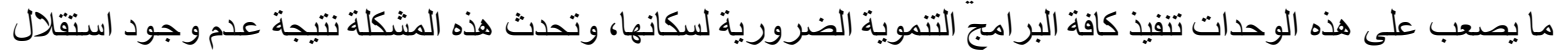

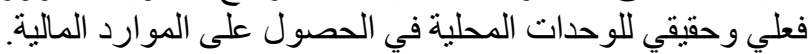

ع - النتائج و التوصيات

أولا : النتائج

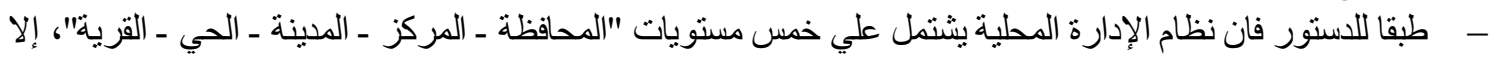

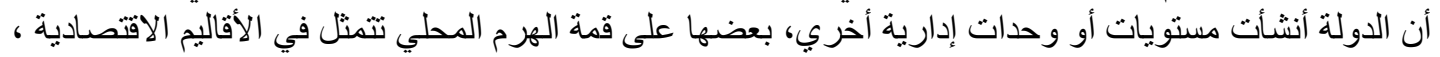

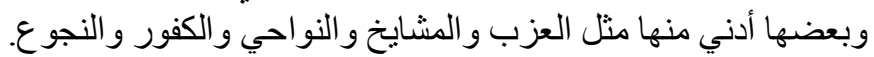

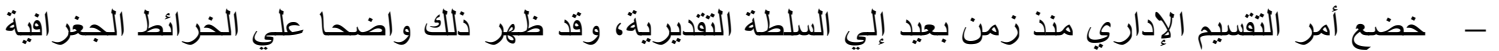

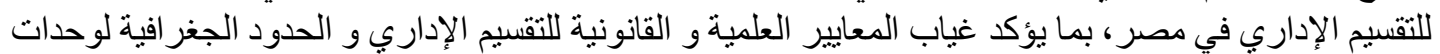

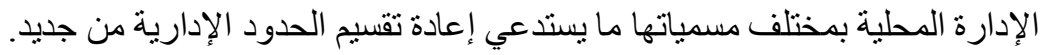

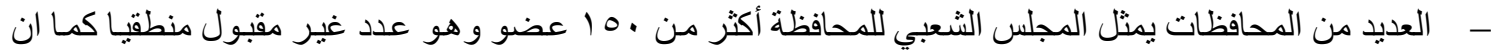

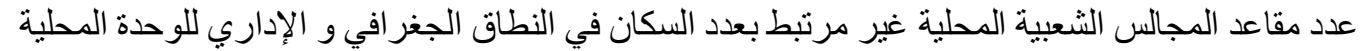

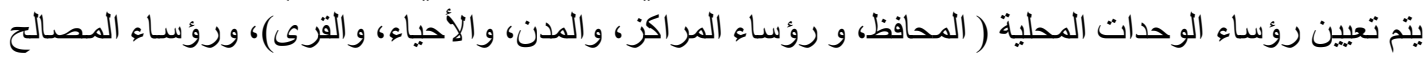

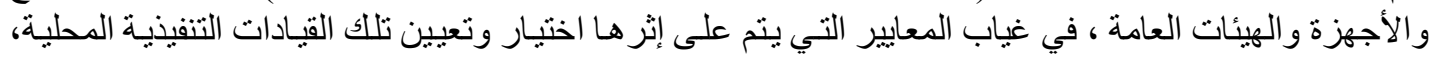
مما يؤثر علي الكفاءة. 


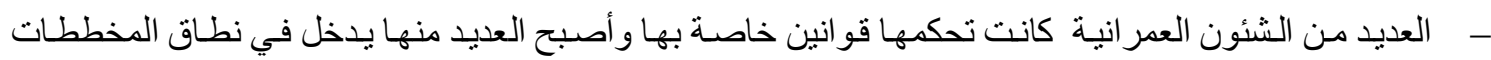

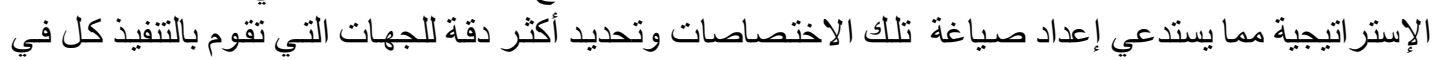

دائرة اختصاصنه

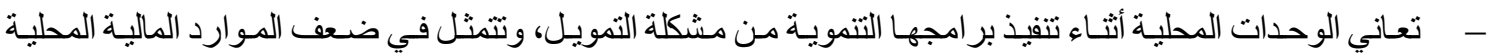

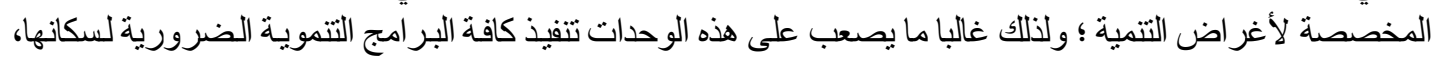

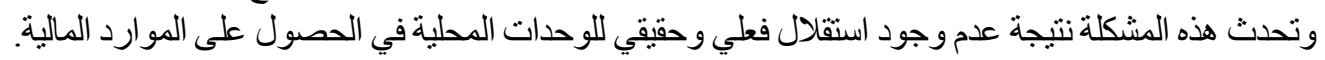

ثانيا : التوصيات

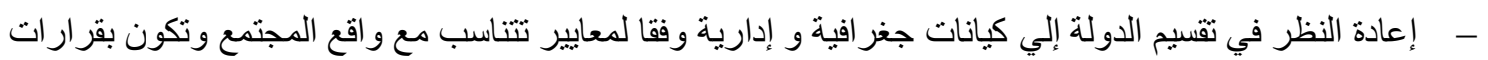

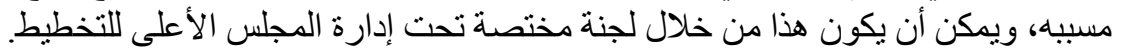

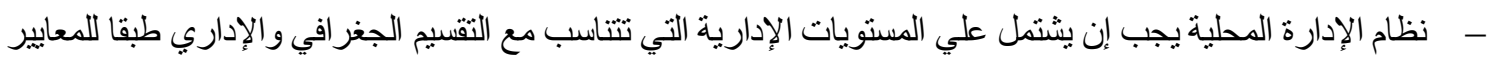

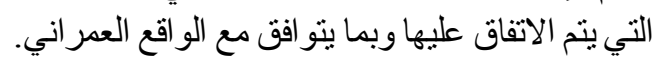

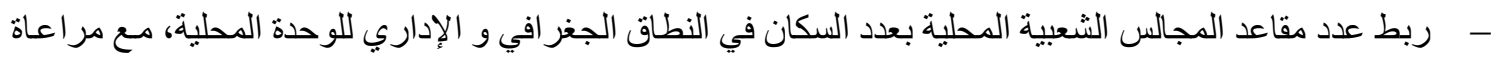

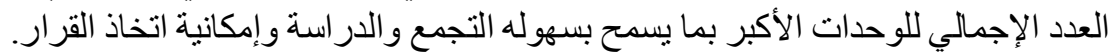

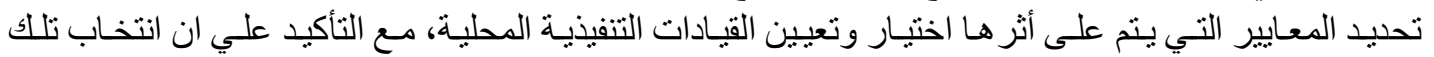

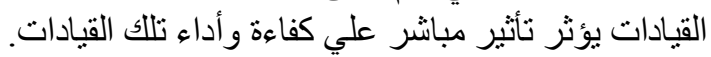

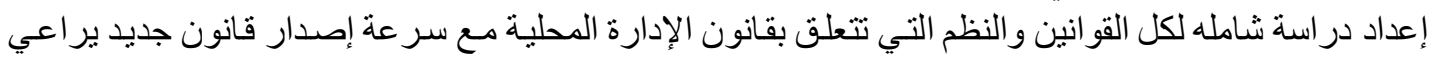
كل العو امل التي تنؤثر علي الإدارة المحلية. - العمل علي وجود استقلال فعلي وحقيقي للوحدات المحلية في الحصول على الموارد المالية.

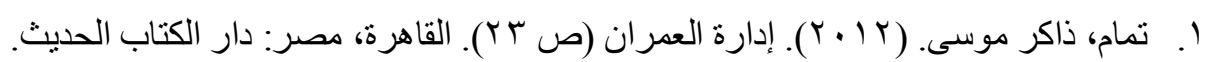

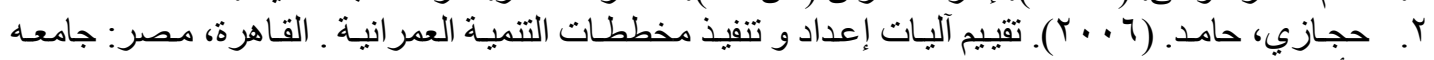

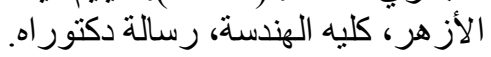

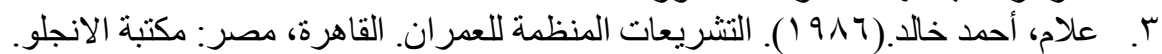

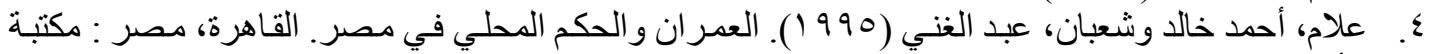
الأنجلو المصرية.

๑. عبد الحميد، عبد المطلب. ( ( . ب). التمويل المحلي و التتمية المحلية. الإسكندرية، مصر: الدار الجامعية

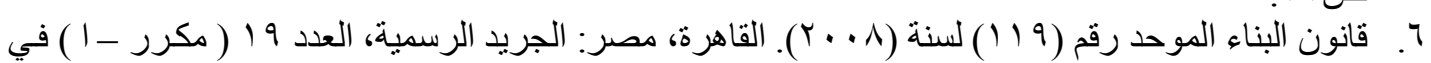

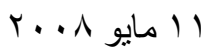

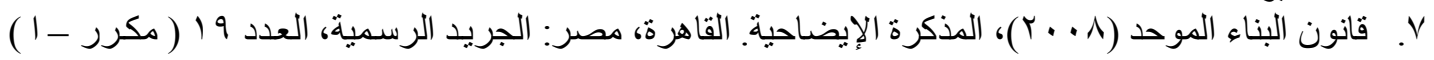

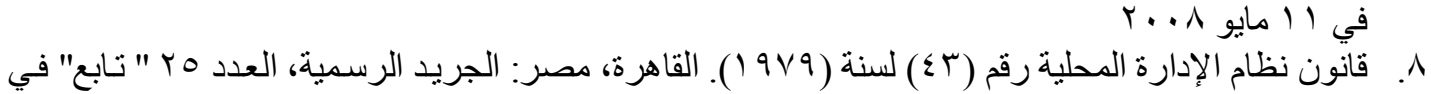
19V9/T/Y)

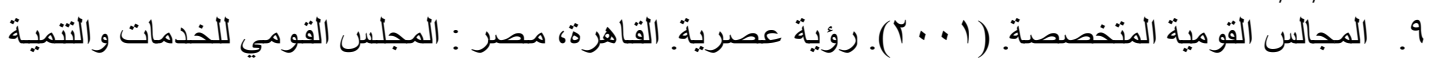
الاجتماعبة الاعت

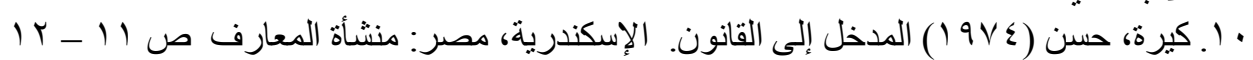

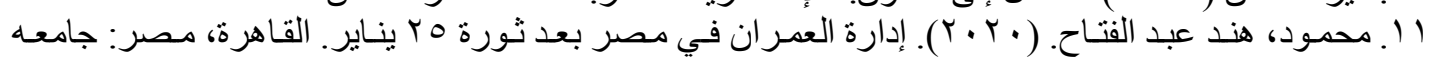

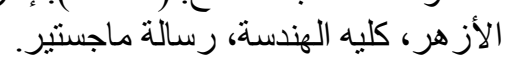

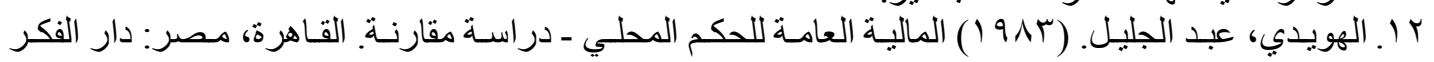

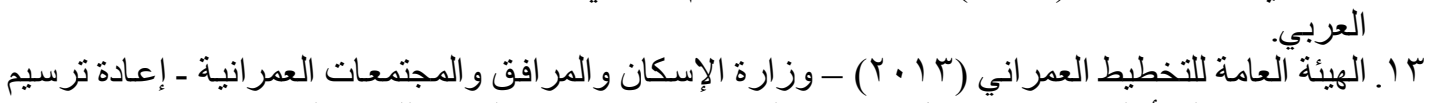
حدود مصر إلى أقاليم تنموية ـ تفعيل توجهات المخطط الاستر اتيجي القومي للتنمية العمر النية.

14. Kenneth, J. Davey ( 1993). Elements of urban management, Washington, D.C. : Published for the Urban Management Program by the World Bank 